\title{
The Effects of Ideology and Group Ties on Loyalty Decision-Making \& Evaluation
}

\author{
Rebecca Sue Frazier \\ Charlottesville, VA \\ Master of Arts, University of Virginia, 2012 \\ Bachelor of Science, University of Richmond, 2009
}

\begin{abstract}
A Dissertation presented to the Graduate Faculty
of the University of Virginia in Candidacy for the Degree of

Doctor of Philosophy
\end{abstract}

Department of Psychology

University of Virginia

May, 2015 


\section{The Effects of Ideology and Group Ties on Loyalty Decision-Making \& Evaluation}

Thousands of American children start their school day with following words "I pledge allegiance to the Flag of the United States of America, and to the Republic for which it stands, one Nation under God, indivisible, with liberty and justice for all." Before they can even understand the meaning of what they are saying, we teach children that loyalty is a central value. However, we rarely talk about the complexities of how loyalty operates in practice and what it means to put the interests of our country (or other groups) ahead of our own.

While we may love our groups, we also love ourselves. Human beings exhibit a host of egotistical biases that result in viewing the self as more justified than others in acting selfishly (see Ross \& Sicoly, 1979 and Shepperd, Malone, \& Sweeny, 2008 for a review). These biases may at least partially explain why when serving one's group requires a cost to the self many individuals may not choose to oblige. In any given situation personal interests may seem more important than the interests of the group, and yet for groups to function effectively individual sacrifices may be required. So, how do individuals decide when they (or others) should display loyalty or act prosocially towards fellow group members? And how do they evaluate others who are making these same decisions?

The answer to that question depends in part upon the ties between the individual and the group. People do not care about all of their group memberships equally - social identities are complex and some groups are more central to identity than others (Brewer, 2009). Closeness and similarity to the other group members also matters. Few people are likely to sacrifice their safety, time, or money for someone they've never met compared to their close friends (Piliavin, Dovidio, Gaertner, \& Clark, 1981). Expectations may be similar for others. Fellow close group members may be expected to display greater loyalty, and betrayals may be judged more harshly 
than those by more distant group members, or members of outgroups.

In this dissertation, I will investigate whether decisions to show and value loyalty are more than a function of our ties to the group. I will test the hypothesis that ideological beliefs, and the interaction between political ideology and ties to the group, contribute to decision making about group loyalty. First, I will review literature showing that differences in political ideology may impact how individuals value loyalty and their general orientation towards groups. Next, I will review the literature on ingroup favoritism in order to explain why and how the individual's ties to the group may impact decision-making. Finally, I will conclude by presenting evidence for a possible interactive effect of ideology and group ties on group prioritization behaviors and evaluations. The empirical investigation of this possibility will include three studies that investigate this effect for both the individual's personal decision-making (Study 1a and 1b) and their evaluations of the decision-making of others (Study $2 \& 3$ ).

\section{Ideology and Group-Oriented Beliefs}

Ideology can be thought of as "an interrelated set of moral and political attitudes that possess cognitive, affective, and motivational components" and which "help to explain why people do what they do" by "organiz(ing) their values and beliefs and lead(ing) to political behavior" (Jost, 2006, p. 653). Ideology is linked to voting behavior, evaluations of political candidates and parties, and attitudes on policy issues (Abramowitz, 2012; Jost, Banaji, \& Nosek, 2004; Jost, Fitzsimons, \& Kay, 2004). Political ideology is also associated with a wide range of factors outside of the political arena-- such as personality (see Mondak, 2010 for a review), sensitivity to threat (Feldman \& Stenner, 1997), sensitivity to disgust (Inbar, Pizarro, \& Bloom, 2009) and the need for cognitive closure (Chirumbolo, Areni, \& Sensales, 2004). Differences in liberal and conservative ideology may also be important to understanding 
how individuals relate to groups. Liberal ideology emphasizes promoting equality and nurturing the interests of the individual, while conservative ideology emphasizes respecting authority and enforcing a strict moral code (Hunter, 1991; Lakoff, 2002; Hetherington \& Weiler, 2009). While both liberals and conservatives are interested and invested in groups, they may be inclined to view the proper relationship between the individual and the group differently.

Liberal Group-Orientation. In general, liberals tend to prefer more communal and equitable relationships within their groups and are likely to prioritize the interests of the group when doing so promotes fairness or prevents harm to fellow group members. According to Moral Foundations Theory (Graham, Haidt, \& Nosek, 2009, Haidt \& Graham, 2007; Haidt, Graham, \& Joseph, 2009; Haidt \& Joseph, 2004) liberal ideology is largely focused on the moral foundations of harm and fairness and as such liberals primarily decide if an action is morally right or wrong based on the extent to which it causes or prevents harm and is fair to the parties involved.

Liberals are also consistently more universalistic in their group orientations and are more likely to endorse self-transcendence values which focus on promoting equality and helping all others (Schwartz, Caprara, \& Vecchione, 2010). Liberals are more likely to believe that human nature is fundamentally good and that the ultimate good is to overcome self-interest and live in harmony with others (the unconstrained vision of human nature, see Sowell, 2002). One particularly striking example of this belief can be found in John Lennon's song "Imagine" in which he asks listeners to imagine a world with "no countries... nothing to kill or die for and no religion too... a brotherhood of man..." where people "share the world" and "live as one," (Lennon, 1971). Lennon's words personify the liberal universalistic vision for humanity and may lend insights into the factors which could lead liberals to be wary of loyalty to any groups. 
Liberals' greater valuing of self-transcendence and fairness may also explain evidence suggesting that liberals are more likely to display prosocial behaviors in groups than conservatives, even when interacting with individuals they do not know. Liberals report a greater desire to help groups such as the poor through social welfare programs, universal health care, and foreign aid (Rathbun, 2007). Furthermore, liberals are more likely to have a prosocial social value orientation (SVO; Van Lange, 2000) than conservatives-- expressing an increased desire to help anonymous others across a series of simulated giving scenarios (Van Lange, Bekkers, Chirumbolo, \& Leone, 2012; Sheldon \& Nichols, 2009). Higher levels of SVO are correlated with increased giving in tasks such as the public goods dilemma and prisoner's dilemma game (Kollock, 1998; McClintock \& Van Avermaet, 1982) so there's good reason to believe that liberals may be more inclined to favor the group and act cooperatively in these types of situations. However, it's unclear how this tendency to act prosocially oneself would influence liberals' judgments about the behavior of others. Liberals' increased tendency to act prosocially themselves might make them more likely to negatively evaluate others who do not act in the interests of the group or it may lead them to be more likely to express compassion and forgive the disloyal actions of others.

Conservative Group-Orientation. Conservatives tend to be more oriented towards tight, traditional, and hierarchical group relationships and should thus be likely to prioritize the interests of the group when doing so displays ingroup loyalty or respect for authority (Haidt \& Graham, 2007; Pratto, Sidanius, Stallworth, Malle, 1994). Much like their liberal counterparts, conservatives do value the "individualizing" moral foundations of care and fairness, yet they also report valuing the "binding" or group-oriented moral foundations of respect for authority, ingroup loyalty, and purity/sanctity (Haidt, Graham, \& Joseph, 2009; Van Leeuwen \& Park, 
2009). As such, when making moral judgments conservatives are more likely than liberals to view an action as immoral simply because it involves betrayal of the group, subversion or disrespect for authorities, or impurity (Graham \& Haidt, 2011; Graham, Nosek, Haidt, Iyer, Koleva, \& Ditto, 2011). To the extent that these moral foundations are thought to exist primarily to bind people to their groups, it's also possible that individuals who care about these group-oriented moral values (ingroup loyalty in particular) should be more likely to put group interests ahead of their own than those who do not.

Additionally, for conservatives the effects of loyalty on group prioritization decisions may be intensified when the individual has close ties to the group at hand. While liberals may be more likely to support broad or universalistic groups (or rather, the erasure of local or national groups), conservatives seem to be more parochial and are particularly invested in furthering the interests of their close ingroups (Schwartz, Caprara, \& Vecchione, 2010). Conservatives view human nature as fundamentally self-interested and something which should be constrained by strong institutions and hierarchy (the constrained vision of human nature, see Sowell, 2002). Furthermore, conservatives tend to support social hierarchies which put their group ahead of other groups-- thus displaying loyalty only to their local ingroup (see work on Social Dominance Orientation-- Sidanius \& Pratto, 1999). A similar pattern emerges for conservatives' religious ties and giving behaviors. Brooks (2006) presented evidence that conservatives are both more likely to report attending religious services and more likely to donate to charities. However, the charities that conservatives donate to are largely religious in nature thus showing a greater tendency to act prosocially towards members of relevant ingroups. This suggests that the relationship between the individual and the group at hand may be especially relevant for conservative's group prioritization decisions. 


\section{Ties to the Group and Group-oriented Behavior}

It should not be surprising that ties between the individual and the group can be strong predictors of one's own prosocial behavior and expectations about the behavior of others. Groups are one of the most fundamental elements of human functioning-- indeed, human beings have evolved to live in groups (Wilson, Van Vugt, \& O'Gorman, 2008) and consistently show a basic and fundamental need to belong (Baumeister \& Leary, 1995). According to social identity theory (Tajfel \& Turner, 1986) identities and self-esteem are derived from group memberships. As a consequence, people are deeply motivated to support and protect their groups.

This increased overlap between self and group identity often leads people to favor ingroup members over outgroup members. Even in minimal groups people like members of their own group more (Tajfel \& Turner, 1979; Tajfel \& Billig, 1974; Brewer \& Karmer, 1985; Hogg \& Sunderland, 1991) and are more prosocial toward fellow ingroup members than to outgroup members (Brewer, 1979; Wilder, 1981). These effects are intensified in the presence of a clear outgroup or a threat to the self and in these circumstances individuals rely on group memberships to maintain self-esteem and identity (Brewer, 1979; Meindl \& Lerner, 1984). Furthermore, ingroup members are seen as more similar to ourselves leading us to like them more than others (Byrne, 1971; Rosenbaum, 1986). Perceiving shared ideology, moral beliefs, and attitudes creates greater affinity and ingroup favoritism (Dovidio, 1984; Ehlert, Ehlert, \& Merrens, 1973; Haidt, Rosenberg, \& Hom, 2003; Hornstein, 1982; Piliavin et al, 1981).

In the three studies described here I expected to see strong effects of ties to the group on group-oriented behaviors and evaluations of the behavior of others. However, I also predicted that ties to the group would interact with ideology to predict social behaviors. 


\section{Interactions between Group Ties and Ideology}

Individual Behavior. Individual decisions about when to act selfishly versus cooperatively may be the result of interactions between the individual's ideology and his or her ties to the group at hand. In particular, I predicted that both liberals and conservatives will be more likely to act cooperatively and to negatively evaluate disloyalty when they have strong ties to the group at hand. However, the ties between the individual and the group might be more critical to the decision making of conservatives than liberals. I hypothesized that conservatives' greater parochialism would lead them to be more likely to display loyalty and to negatively evaluate disloyal others when they have strong ties to the group, while liberals' more universalistic orientation would lead them to be less differentiated in their loyalty behaviors and evaluations.

Liberals have been shown to be more prosocial than conservatives in terms of their basic social value orientation (Van Lange et al., 2012; Sheldon \& Nichols, 2009) but these effects may be driven by a lack of ties between the individual and the group. In the typical SVO task individuals are asked to imagine interacting with an anonymous other whom they've never met and will never meet in the future. This type of interaction may appeal to liberals' greater desire to care for and protect others, but for conservatives who are higher in SDO the idea of helping an anonymous other may seem unrealistic and off putting. However, if conservatives were asked to interact with someone who was a member of their ingroup, it's possible that their greater valuing of ingroup loyalty may lead them to be more prosocial than their liberal counterparts. As such, in Study $1 \mathrm{a}$ and 1b, I manipulated the ties between the individual and their fellow group member(s) and investigate the extent to which behaviors on a prisoner's dilemma task and a public goods game vary as a function of the individual's ideology and their ties to the group. In particular, I 
hypothesized that there would be an interaction such that liberals are more prosocial than conservatives when interacting with anonymous others but conservatives are more prosocial than liberals when interacting with close others.

Evaluations of Others. Evaluations of the group prioritization decisions of others may also be the result of interactions between ideology and ties to the individual being evaluated. In general people expect ingroup members to loyally put the interests of the group ahead of themselves, but differences in liberals' and conservatives' valuing of ingroup loyalty may lead them to differ in their evaluations of the immorality of disloyal actions and of the individual committing the actions. As such, I predict that both liberals and conservatives will evaluate disloyal ingroup members negatively, but this effect will be larger for conservatives than liberals.

Schlenker, Chambers, \& Le (2012) showed that conservatives were less likely to allow transgressions than liberals (cheating on taxes, lying, etc.), scored higher on measures of moral integrity (duty, honor, loyalty, etc.), and generally favored equity over equality. These findings suggest that conservatives may be especially harsh on close others who betray them or act against the interests of the group relative to anonymous others. However, it is also possible that conservative's closer ties to the individual could make them more likely to forgive someone with whom they share strong group ties.

In Study 2 and 3, I tested these two competing hypotheses by having subjects evaluate the loyalty and morality of potentially disloyal action and the person who committed it. More specifically, I attempted to understand how ideology and valuing loyalty impacts evaluations of others who have committed a disloyal action within the context of either strong group ties (situations in which the group has been through a lot together) and weak group ties. I predicted that there would be an interactive effect such that I conservatives would be harsher than liberals 
on ingroup members who displayed disloyalty towards the group in the context of strong group ties.

\section{Study 1a Method}

\section{Participants}

Participants were 1,831 adults ${ }^{1}$ (64.4\% female; $96.7 \%$ U.S. Citizens, mean age $=32.50$, $S D=14.56$ ) who visited the Project Implicit research website (https://implicit.harvard.edu/) and volunteered to be randomly assigned to complete this study from a small pool of available studies. $69.9 \%$ of participants were Caucasian, $12.1 \%$ African American, and 18\% other. In terms of political ideology $56 \%$ of participants reported being socially liberal, $24 \%$ moderate, and $20 \%$ socially conservative. For social ideology in particular, $67 \%$ of participants reported being socially liberal, $15 \%$ moderate, and $17 \%$ socially conservative. For economic ideology in particular, $46 \%$ reported being economically liberal, $24 \%$ moderate, and $30 \%$ economically conservative.

\section{Materials}

Political Ideology Questionnaire. Subjects answered 5 questions (in random order) about their political ideology. Using a 7-point Likert scale (from Strongly Liberal to Strongly Conservative) they were asked to report their overall political identity, and then their political identity on social issues (eg. abortion, gun control, gay rights) and economic issues (eg. taxation and government spending). Subjects also reported their political party identification (Republican, Democrat, Independent, Libertarian, Green, or Other) and estimated what percentage of people in their community they believed shared their political views (0\%-100\% in 5\% intervals).

\footnotetext{
${ }^{1}$ This number represents the full sample but the sample size may vary by item or analysis due to missing data.
} 


\section{Nine-item Decomposed Social Value Orientation Game (aka Triple Dominance}

Measure). To measure social value orientation I used the scale developed by Van Lange, Otten, De Bruin, \& Joireman (1997). Participants imagined that they had been randomly paired with another person whom they did not know and would not meet in the future. They were then told that both they and the other person would be making choices among three different points payoff matrices in which every point has value so that the more points they received the better that would be for them and the more points the other received the better that would be for him or her. Participants then selected from three possible options for point values across nine decomposed games and were classified using the scoring algorithm of Van Lange et al. (1997) as having either a pro-self/individualistic (those who assigned to themselves the highest point value of the three choices), pro-social (those who assigned points equally across themselves and the other), or competitive social orientation (those who assigned points based on the option that held the greatest difference between values). Each participant's average social value orientation score is represented as the average of their decisions across the nine dilemmas and ranges from 1-3 $(1=$ Most Prosocial, 2 = Egotistic, 3 = Competitive) with lower values being more prosocial.

Moral Foundations Questionnaire. I used the loyalty and fairness subscales (12-items total) of the Moral Foundations Questionnaire from Graham, Nosek, Haidt, Iyer, Koleva, and Ditto (2011). Participants evaluated how relevant certain concerns were to their judgments of right and wrong using a 1-6 scale from 1:"Not at all Relevant" to 6:"Extremely Relevant". Participants read three statements regarding the moral importance of loyalty (e.g., "Whether or not someone did something to betray their group") and three statements regarding the moral importance of fairness (e.g., "Whether or not some people were treated differently from others"). Participants also rated their agreement with several moral statements using a six point scale from 
1: "Strongly Disagree" to 6: "Strongly Agree." Three of the items measured loyalty as a moral value (e.g., "People should be loyal to their family members, even when they have done something wrong") and three of the items measured fairness as a moral value (e.g., "Justice is the most important requirement for a society.”).

Public Goods "Give-Some" Dilemma. Using a modified version of the procedure from DeCremer and Van Vugt (2002) participants imagined that they had been given $\$ 30$ and were part of a group of 9 of their closest friends and family (or 9 anonymous individuals who they don't know and would never meet). Participants were free to contribute any amount they wanted to a common pool and that the total amount contributed by the group would be multiplied by two and split equally among all members, regardless of their contribution. So, the more that each individual chose to contribute, the more that everyone benefitted. However, non-contributors could reap the rewards of others' sharing when they did not.

The participants were presented with an instructions page on which a table detailed how the distribution of funds worked if the participants decided to give a certain amount. After reading the instructions page, they were asked "Knowing that whatever amount you contribute will be doubled and distributed equally among your fellow group members, how much of your $\$ 30$ would you like to contribute?" and were presented with all the full dollar amounts from $\$ 0$ to $\$ 30$.

Prisoner's Dilemma Game. I used a I've variation of the common single-shot prisoner's dilemma game paradigm in which subjects are asked to make a decision about whether to confess to a crime they have committed with someone else or deny participating. Subjects were presented with a vivid scenario in which they were asked to imagine that they had been drinking at a bar one day with either a close friend or someone whom they just met. Participants were told 
that the bartender was leaving the cash drawer unattended every few minutes and that after a few drinks they (along with their companion) had impulsively decided to rob the bar. After robbing the bar they ran off with their partner, divided up the money, and were then apprehended and held by the police. The participants were then faced with a choice: they could confess to the crime and take a deal with the police, or they could deny having taken part in the crime. If they confessed and testified and their accomplice denied taking part in the crime, then they could go free and their "partner" would go to prison for ten years. However, if the partner confessed and they denied participating in the crime then they would go to prison for ten years and their "partner" would go free. Finally, if they both confessed they would serve six years each and if they both denied taking part in the crime they would both go to prison for six months. In this situation, subjects must choose between keeping silent and cooperating with their partner or competitively taking the deal and potentially forcing their partner to serve the extended sentence.

\section{Procedure}

Volunteers were randomly assigned to complete this study from the Project Implicit research study pool. In order to be assigned to the study participants must have registered for an account on Project Implicit.org and completed an initial demographic questionnaire (measuring age, gender, ethnicity, race, religion, zipcode, citizenship). Subjects who reported being US citizens and who had not previously completed the study were then presented with a block of questionnaires (political identification, social value orientation, and moral foundations) in a random order, and either the public goods dilemma or the prisoner's dilemma. Participants were randomly assigned to receive the "anonymous" or "close" other(s) condition for the social dilemma they received. The order of the block of questionnaires and the social dilemma game was randomized. The order of measures did not qualify any of the reported results. At the 
conclusion of the study all subjects were then asked to complete a Political Identification IAT (Republican/Democrat-Self/Other) and were given feedback about their results and debriefed about the purpose of the study. The IAT task was included in order to meet participant expectations on the site but was not critical to the study and as such will not be included in the analysis reported here.

\section{Study 1a Results}

\section{Public Goods Dilemma Results}

Condition Effects. As hypothesized, on average, participants gave more money to the common pool in the public goods dilemma when donating to a group of close friends $(M=$ $24.51, S D=8.84)$ than to anonymous others $(M=22.10, S D=9.74)$. This main effect was significant in the ANOVA model predicting giving behavior from condition, social politics ${ }^{2}$, and their interaction, $F(1,1188)=4.50, p=.034, \eta_{p}^{2}=.004$.

Social Politics Effects. I expected that liberals would give more than conservatives in the anonymous public goods condition, but did not predict any significant difference between liberals and conservatives on average in the friend condition. Contrary to my predictions, there was a small effect suggesting that conservatives gave less in the public goods game $(M=22.48$, $S D=10.41)$ than liberals $(M=24.01, S D=8.95)$ and this effect was significant in the overall ANOVA model predicting giving behavior from condition, social politics, and their interaction, $F(1,1188)=8.54, p=.004, \eta_{p}^{2}=.007$

Social Politics by Condition Interaction. I also predicted that social politics and condition would interact causing conservatives to donate more than liberals in the friend condition and to

\footnotetext{
${ }^{2}$ I present results across all three studies in terms of the effects of social politics since social politics should be more closely tied to ideology and moral intuitions than ratings of overall politics. Analyses for overall politics, economic politics, and party identification are available upon request.
} 
give less/defect more than liberals in the anonymous condition. This hypothesis was not supported by the data. In an ANOVA predicting giving behavior by social politics, condition, and their interaction there was no significant interaction, $F(1,1188)=0.27, p=.601, \eta_{p}{ }^{2}=.000$ (see Figure 1). There was evidence of a small but significant correlation $(r=-0.093, p<.05)$ between social politics and giving behavior in the anonymous public goods dilemma condition such that an increase in conservatism was associated with decreased giving (see Table 1). However, this correlation was small in magnitude and there was no evidence to suggest that conservatives gave more when interacting with their friends (again see Figure 1).

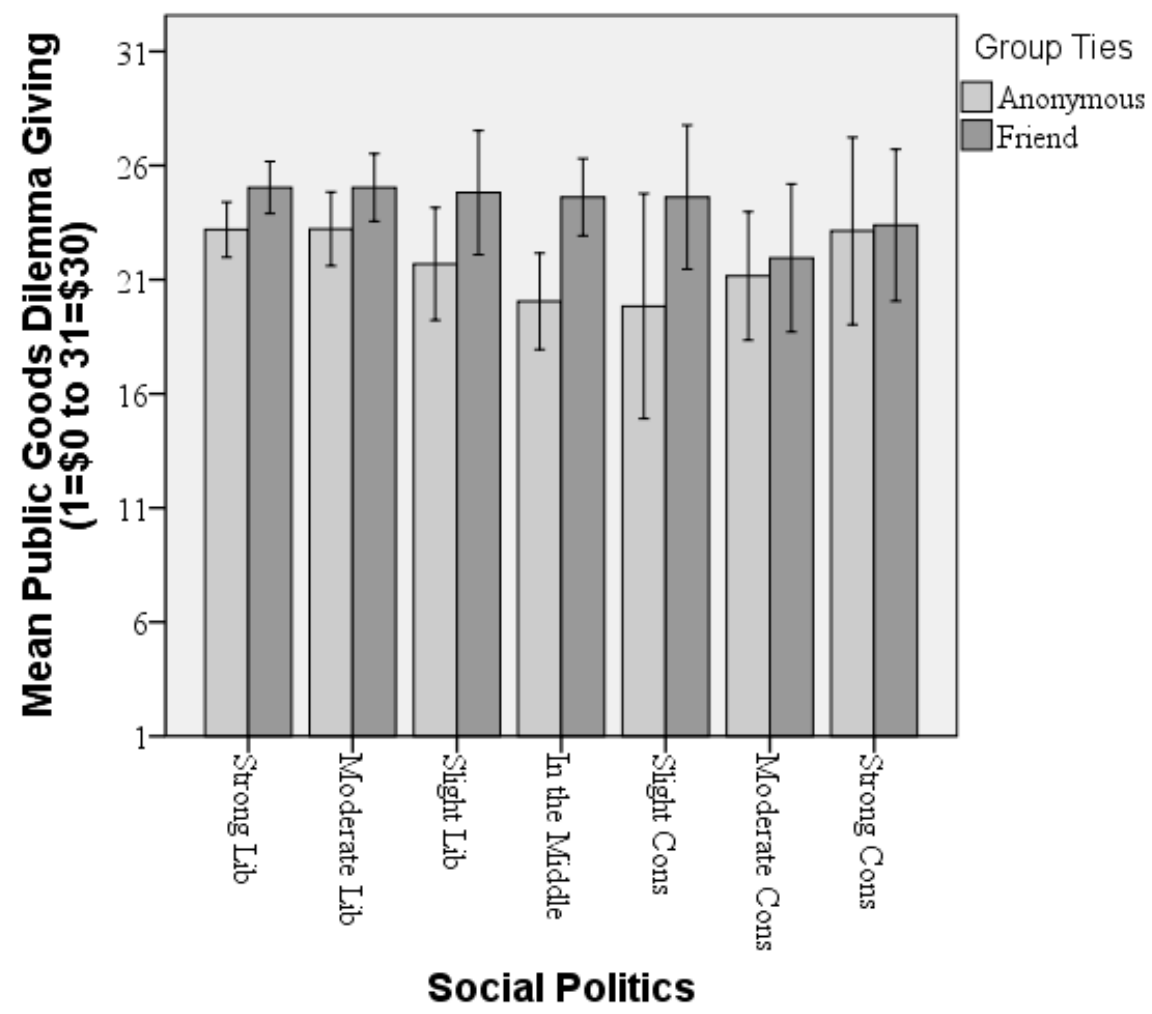

Figure 1. Study 1a Mean Public Goods Donations Ratings by Social Politics and Group Ties. Note: Error bars represent $95 \%$ confidence intervals. 
Prisoner's Dilemma Results

Condition Effects. As I had predicted, in the prisoner's dilemma game, participants were slightly more likely to deny participating in the crime when the partner was a close friend $(M=$ $1.32, S D=.47)$ rather than an anonymous other $(M=1.24, S D=.43)$. This effect was small but statistically significant in the ANOVA predicting decision making in the prisoner's dilemma task from condition, social politics, and their interaction, $F(1,1163)=7.44, p=.006, \eta_{p}{ }^{2}=.006$.

Social Politics Effects. Again, as hypothesized there was no significant main effect of politics on behavior in the prisoners dilemma game in the model predicting behavior by social politics, condition, and their interaction, $F(1,1163)=1.83, p=0.176, \eta_{p}^{2}=.002$.

Social Politics by Condition Interaction. I predicted that social politics and condition would interact causing conservatives to be more likely to deny than liberals in the friend condition and to confess more than liberals in the anonymous condition. This hypothesis was not supported in the data. In the ANOVA predicting decision making in the prisoner's dilemma task from condition, social politics, and their interaction there was no interaction, $F(1,1163)=1.01, p$ $=.314, \eta_{p}^{2}=.001$ (see Figure 2). There were also no significant correlations between social politics and responses to the prisoner's dilemma task (see Table 1). 


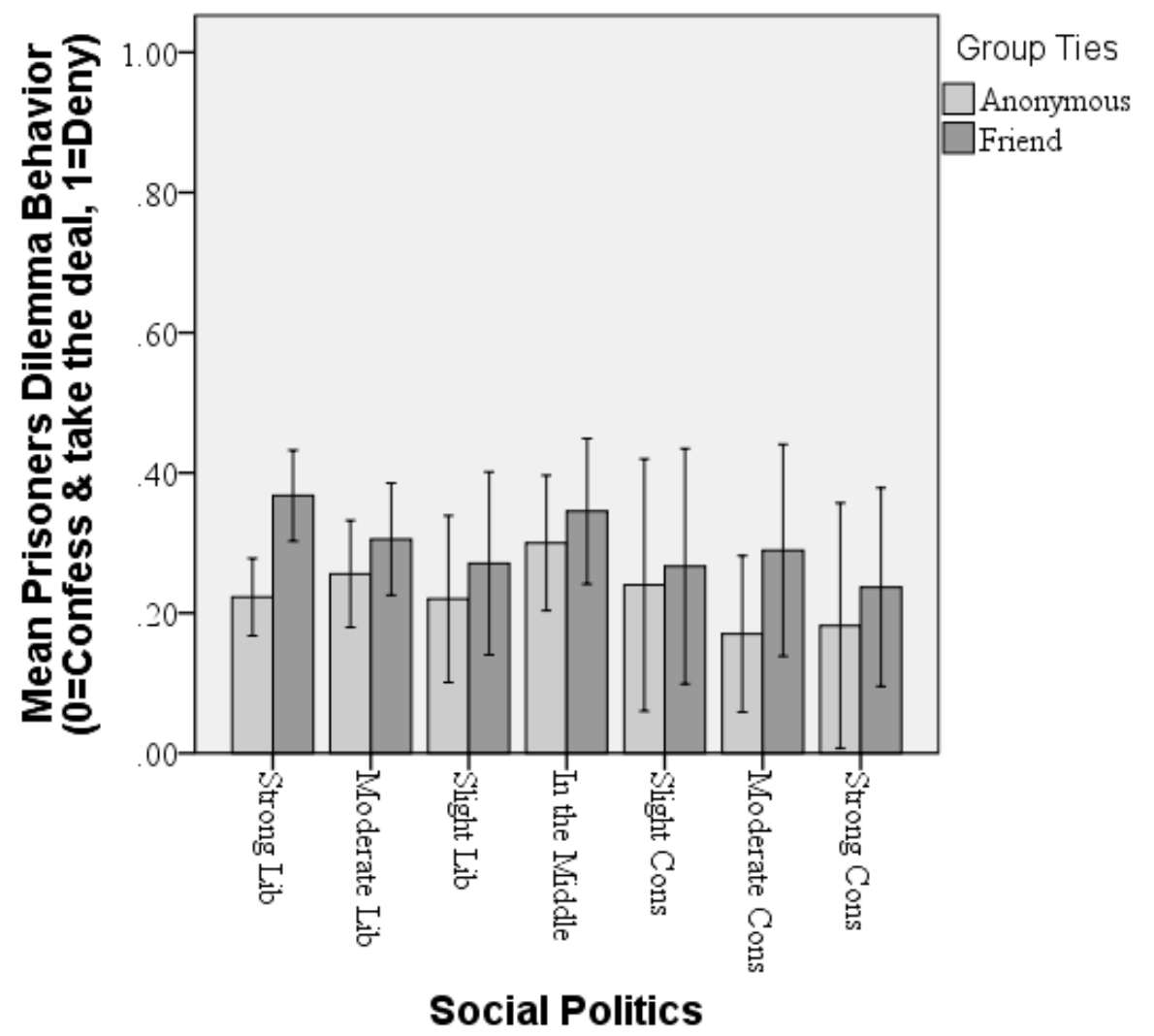

Figure 2. Mean Prisoner's Dilemma Decisions by Social Politics and Group Ties (Friend v. Anonymous Other). Note: Error bars represent 95\% Confidence Interval

Social Value Orientation and Moral Foundations Questionnaire Scores

Social Value Orientation. As predicted, I also found a strong correlation between responses to the social value orientation scale and politics such that liberals were consistently higher in prosocial orientation than conservatives (see Tables $2 \& 3$ ). Ratings on the SVO scale were also significantly positively correlated with increased giving behavior on the public goods game both for anonymous others and for friends as well (see Table 4). This relationship between giving and prosocial scores on the SVO has been shown in prior research (see Kollock, 1998 for a review), but this study is the first to show a relationship between prosocial behavior and giving 
among friends.

Moral Foundations Questionnaire. As expected, I also found that responses to the loyalty and fairness subscales of the moral foundations questionnaire were significantly correlated with social, economic, and overall political identity such that conservatives were consistently more likely to endorse loyalty, while liberals were more likely to endorse fairness (see Table $2 \&$ Table 3). However, I was surprised to find that ratings on the Moral Foundations Questionnaire were not significantly correlated with behavior on either of the social dilemmas (see Table 4). In particular, I had predicted that individuals who placed a high moral value on loyalty should be more likely to act prosocially or display loyalty when interacting when a close friend rather than an anonymous other but this did not occur.

\section{Study 1a Discussion}

Study 1a showed that participants donate slightly more to a common pool in the public goods dilemma and deny more (showing greater loyalty to their partner) in the prisoner's dilemma game when playing with friends rather than anonymous others. There is also weak evidence to suggest that conservatives may give slightly less than liberals in the public goods game, but no clear evidence of ideological differences on the prisoner's dilemma game and there were no significant interactions of ideology and behavior on either of the social dilemmas.

I also replicated prior findings showing liberals score higher in prosociality on the SVO scale and higher in Fairness on the MFQ while conservatives score lower on prosociality on the SVO scale and higher on Loyalty on the MFQ. My results also align with prior research showing that individuals with a prosocial orientation donate more in the public goods dilemma, although I did show that SVO scores are generally not related to behavior on the prisoner's dilemma task. Finally, I was surprised to find a lack of evidence to support a relationship between scores on the 
MFQ and behavior in either social dilemma. I had expected to find that individuals who placed a greater value on loyalty (typically Conservatives) would give more in the public goods game and cooperate more in the prisoner's dilemma -- especially when interacting with their close friend(s). However, I did not find evidence for an interaction between MFQ loyalty scores and condition in either the public goods dilemma or the prisoner's dilemma.

In Study 1a I presented the instructions for the public goods dilemma in the form of a table of possible outcomes for both the self and others and subsequently more than $50 \%$ of subjects selected the most prosocial option-- giving all of their money to the common pool. As such, I was concerned that this presentation format was artificially inflating the occurrence of prosocial behavior. In order to minimize possible effects of the instruction format in Study $1 \mathrm{~b}$ I decided to systematically manipulate the instruction format and replicate the key effects. I expected more variation in responses and lower giving overall when the information was presented in a list format (as the payoffs for cooperative behavior may be less obvious) but I did not expect the instruction format to interact with the effects of condition or ideology.

\section{Study 1b Method}

\section{Participants}

Participants were 5,025 adult U.S. citizens (65.6\% female; mean age $=29.7, S D=13.6)$ who visited the Project Implicit research website (https://implicit.harvard.edu/) and were randomly assigned to complete this study. $66.5 \%$ of participants were Caucasian, $12.0 \%$ African American, and $21.5 \%$ other. In terms of overall political ideology $52 \%$ of participants reported being socially liberal, $28 \%$ moderate, and $19 \%$ socially conservative. For social ideology in particular, $64 \%$ of participants reported being socially liberal, $18 \%$ moderate, and $18 \%$ socially 
conservative. For economic ideology in particular, 44\% reported being economically liberal, $28 \%$ moderate, and $29 \%$ economically conservative.

\section{Procedure}

The procedure and materials for study $1 \mathrm{a}$ and $1 \mathrm{~b}$ were identical but we manipulated whether the instructions in the public goods and prisoner's dilemma tasks were accompanied by a table of possible outcomes or an instructions page without a table. The presentation of the table depended on whether the prior game included a table as well-- subjects either saw both instructions pages with a table or without one.

\section{Study 1b Results}

Instruction Format Effects. On average, subjects donated more money to the common pool in the public goods dilemma task ${ }^{3}$ when instructions were presented in a table format $(M=$ 23.31, $S D=9.74)$ than when presented in a non-table format $(M=20.83, S D=9.74)$ but the instruction format did not significantly interact with condition or social politics (see Table 5). As such, I will present the results from here on by collapsing across the table and no-table instruction conditions.

\section{Replication of Public Goods Dilemma Results}

Condition Effects. As hypothesized, on average, participants gave more money to the common pool in the public goods dilemma when donating to a group of close friends $(M=$ 23.12, $S D=9.31)$ than anonymous others $(M=21.01, S D=9.83)$. This main effect was significant in the ANOVA model predicting giving behavior from condition, social politics, and their interaction, $F(1,4281)=11.82, p=0.001, \eta_{p}{ }^{2}=.003$.

\footnotetext{
${ }^{3}$ Note. Data from subjects in the table condition of the prisoner's dilemma game had to be excluded due to an error in the task instructions. Therefore, instruction format results are only presented for the public goods dilemma and data presented in the Study $1 \mathrm{~b}$ prisoner's dilemma results represents only participants in the non-table condition.
} 
Social Politics Effects. I expected that liberals would give more than conservatives in the anonymous public goods condition, but was not predicting any significant difference between liberals and conservatives on average across the friend and anonymous conditions. Contrary to my predictions, there was a small effect suggesting that conservatives gave less in the public goods game $(M=20.83, S D=10.28)$ than liberals $(M=22.64, S D=9.30)$ and this effect was significant in the overall ANOVA model predicting giving behavior from condition, social politics, and their interaction, $F(1,4281)=35.31, p<0.0005, \eta_{p}^{2}=.008$. Furthermore, there was also evidence of a small but significant correlation between social politics and prosocial behavior such that greater conservatism was associated with less contribution to the public donation pool (see Table 6). This replicates and extends the finding from Study 1a by suggesting that conservatives are slightly less prosocial towards both friends and anonymous others.

Social Politics by Condition Interaction. As in Study 1a, we had predicted that social politics and condition would interact but this hypothesis was again not supported. In an ANOVA predicting prosocial behavior in the public goods game by social politics, condition, and their interaction the interaction was not statistically significant $\left(F(1,4281)=.55, p=0.460, \eta_{p}{ }^{2}=\right.$ $.000)$, see Figure 3. 


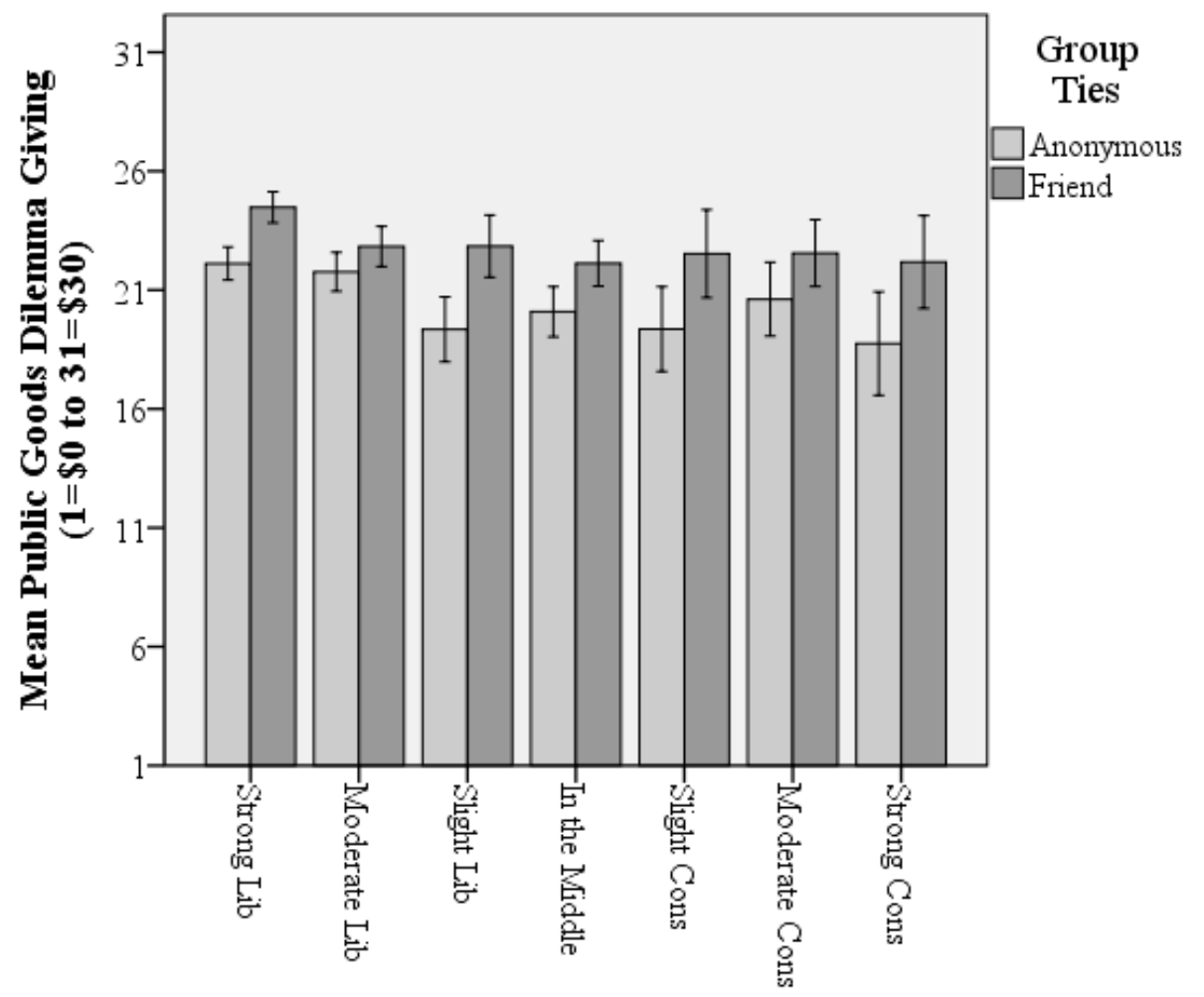

Social Politics

Figure 3. Mean Public Goods Dilemma Behavior by Social Politics and Group Ties (Friend v. Anonymous Other). Note: Error bars represent 95\% Confidence Intervals.

\section{Replication of Prisoner's Dilemma Results}

Condition Effects. As I had predicted, in the prisoner's dilemma game, participants were slightly more likely to deny participating in the crime when the partner was a close friend $(M=$ $1.29, S D=.41)$ than an anonymous other $(M=1.21, S D=.46)$. This effect was small but statistically significant in the ANOVA predicting decision making in the prisoner's dilemma task from condition, social politics, and their interaction, $F(1,2119)=9.19, p=.002, \eta_{p}{ }^{2}=.004$.

Social Politics Effects. Unlike in Study 1a, in Study 1b I did find a significant main effect of politics on behavior in the prisoners dilemma game in the model predicting behavior by social politics, condition, and their interaction, $F(1,2119)=8.07, p=.002, \eta_{p}{ }^{2}=.004$. In particular, 
conservatives were more likely to confess $(M=1.26, S D=.44)$ than were liberals $(M=1.32, S D$ $=.47$ ), the less cooperative option.

Social Politics by Condition Interaction. In the ANOVA predicting behavior in the prisoner's dilemma task from condition, social politics, and their interaction there was again no significant interaction, $F(1,2119)=.24, p=.627, \eta_{p}{ }^{2}=.000$, see Figure 4. However, I observed a very small negative correlation between social politics and behavior in the friend condition of the prisoner's dilemma task $(r=-.067, p=.027)$ such that higher levels of conservatism were accompanied by an increased likelihood of confessing (see Table 7).

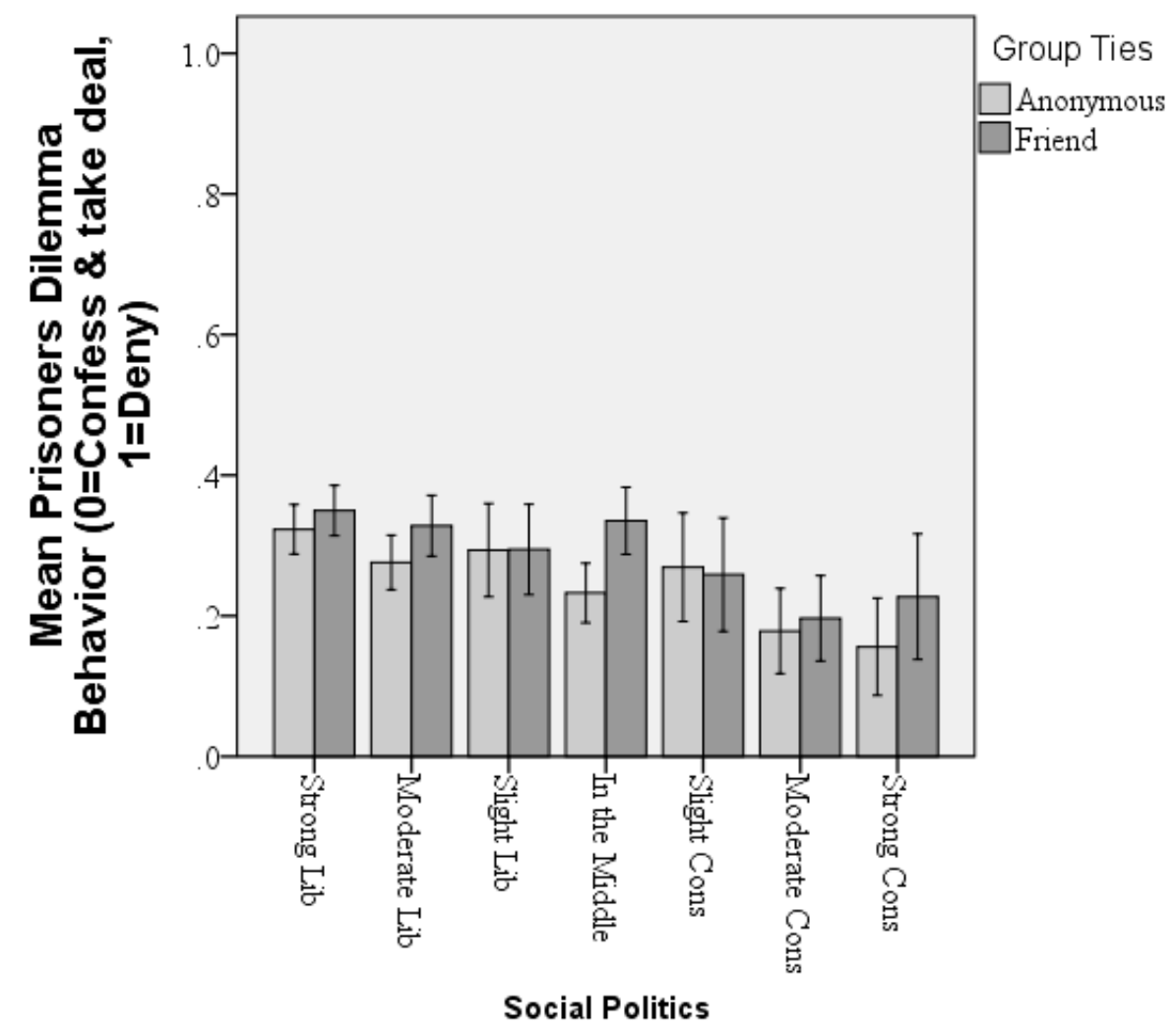

Figure 4. Mean Prisoners Dilemma Behavior Mean by Social Politics and Group Ties (Friend v. Anonymous Other). Note: Error bars represent $95 \%$ Confidence Intervals. 


\section{Social Value Orientation and Moral Foundations Questionnaire Results}

Social Value Orientation. I also replicated Study 1a results showing a strong correlation between responses to the social value orientation scale and politics-- such that liberals were consistently higher in prosocial orientation than conservatives (see Tables 8 \& 9). Ratings on the SVO scale are also once again significantly correlated with giving behavior on the public goods game both for anonymous others and for friends as well (see Table 10). This correlation indicates that a prosocial score on the SVO is correlated with higher giving in the public goods game.

Moral Foundations Questionnaire. Consistent with Study 1a, responses to the loyalty and fairness subscales of the moral foundations questionnaire are significantly correlated with social, economic, and overall political identity such that conservatives were more likely to endorse loyalty, while liberals were more likely to endorse fairness (see Tables 8 \& 9). In Study 1a, ratings on the Moral Foundations Questionnaire were not significantly correlated with behavior on either of the social dilemmas. However, in Study 1b, there was a weak but reliable correlation between MFQ scores and responses to both dilemmas such that individuals with a higher value on loyalty gave slightly less to both friends and anonymous others and individuals with a higher value on fairness gave slightly more in the public goods game (see Table 8) - the opposite of prediction. There was no significant correlation between MFQ scores and decisions in the prisoner's dilemma game (see Table 8)

\section{Study 1b Discussion}

In Study 1b I replicate and extend the results of Study 1a by showing that there are main effects of ideology (liberals say they would cooperate more) and condition (participants cooperate more with friends than anonymous others) but there is no evidence for an interaction 
between ideology and condition. This may suggest that even though prior research has shown that liberals and conservatives vary in their individual valuing of loyalty (Haidt et al., 2009), these differences do not differentially impact their individual group prioritization decisions in online hypothetical social dilemmas. As in study 1a politics was again correlated with scores on the MFQ and the SVO scale. However, in Study $1 \mathrm{~b}$ I also found evidence that individuals who value fairness gave slightly more to the common pool and defected slightly less regardless of whether they were interacting with a close friend or anonymous other. Meanwhile individuals who valued loyalty gave slightly less to the common pool and defected slightly more regardless of who they were interacting with. This finding goes against my initial prediction that conservatives (and those who highly value loyalty) would be more cooperative than those who are less concerned with loyalty when interacting with close friends and others. This may suggest that valuing loyalty is not the same thing as displaying loyalty by cooperating with close others.

However, it is worth noting that the scenarios used here were not directly designed to measure loyalty, per se, but rather tradeoffs between the interests of the individual and the group in a hypothetical online scenario. In order to address this concern I designed Study 2 and 3 to more directly involve evaluations of the disloyal actions of others and to better understand where valuing loyalty does impact judgment. In particular, I hypothesized that valuing loyalty may predict judgments and evaluations of others more than it impacts our own behavior in social dilemmas-- specifically that people who place a high value on loyalty (namely conservatives) would be harsher in their evaluations of others who display disloyalty when this disloyal is committed within a context of strong group ties relative to weak group ties. 


\section{Study 2}

In Study 1a and 1b, I investigated the effects of political ideology and group ties on self vs. group judgments. I found that people are more likely to cooperate with fellow group members when that person(s) is a close rather than anonymous other and that liberals are somewhat more likely to act cooperatively than are conservatives. I had anticipated that conservatives' greater valuing of ingroup loyalty would lead them to cooperate more than liberals when the group members were close others rather than anonymous others, but that did not occur. However, because of its relevance for theory about ideology and moral judgment, I examined this possibility again with a different approach in Study 2. In particular, I investigated whether conservative's greater valuing of ingroup loyalty would lead them to more negatively evaluate fellow group members who had displayed disloyalty — particularly in situations in which the fellow group member has strong ties to the group.

\section{Participants}

Participants were 973 adults $^{4}$ (58.7\% female; $97.9 \%$ U.S. Citizens ${ }^{5}$, mean age $=35.6$ years old) directed to the study from Amazon's Mechanical Turk research website and paid twenty-five cents to participate in the approximately five minute study (overall completion time in seconds: $M=291.7, S D=194.3$ ) By political ideology, $51.1 \%$ of participants self-identified as liberal, $23.6 \%$ as conservative, and $25.2 \%$ as moderate.

\section{Procedure \& Materials}

Following consent, participants completed the same five-item questionnaire from Study

\footnotetext{
${ }^{4}$ This number represents the final sample used for analysis after excluding participants who dropped out of the study prior to reaching the completion page necessary to receive mTurk credit ( $\mathrm{N}=214$ ), participants who took greater than 20 minutes (which is $\sim 4.67 \mathrm{SD}$ above the mean) to complete the study $(\mathrm{N}=8)$, and participants who incorrectly answered more than one of the four manipulation check items $(\mathrm{N}=37)$.

${ }^{5}$ In order to be eligible for this study participants had to have indicated on their mTurk account that they were located in the United States.
} 
1a regarding their political ideology and identification. Next, they were randomly assigned to read two (out of a total of eight) short moral evaluation scenarios describing the actions of a fellow ingroup member who had committed a potentially disloyal action. After reading each scenario subjects completed two manipulation check items to ensure that they had correctly comprehended the prompt and three evaluation items in which they rated how moral the action was, how the loyal the action was, and how positive or negative they felt about the actor. Finally, subjects completed a short demographics questionnaire and were debriefed.

Moral Evaluation Scenarios. Participants read two short (1-2 paragraph) scenarios describing the potentially disloyal actions of a fellow group member. The eight different scenarios varied by the group context and the strength of group ties. Four unique group contexts were used: (1) Family-- Your brother chooses to hire a slightly more qualified candidate over your other brother, (2) Defection-- Your coworker decides to leave your company for a better paying job, (3) Whistleblowing-- Your coworker decides to release controversial preliminary findings from a company study to the press, and (4) Team-- Your teammate decides to switch to an opposing team to receive greater playing time. Each context had two versions: strong group ties or weak group ties. The weak group ties condition presented the scenario without much information about the strength of group bonds. The strong group ties condition added a description of how you and your fellow group members bonded by facing and overcoming challenges together. For example, in the strong group ties family condition participants are asked to imagine that their parents were involved in a tragic car accident and their family really had to bond together and take on odd jobs to survive. However, in the weak group ties family condition no information about the history of the family is included (See Appendix B for a full listing of each of the eight moral evaluation scenarios). 
Each participant evaluated two scenarios — one with strong group ties and one with weak group ties-- each from a different context than the first. Selection was quasi-random. Participants who received a family scenario received a defection scenario at the other level of group ties. Participants who received a whistleblowing scenario received a team scenario at the other level of group ties.

Manipulation Checks. After reading each scenario participants answered two brief manipulation check questions that assessed comprehension and bolstered the manipulation. First participants identified their relation to the target individual-- "Who was Bob?" A: Your brother, B: Your coworker at the startup company Galaxy, C: Your coworker at the Pharmaceutical company Flaxo, or D: Your teammate. Next, they identified the individual's key action -- "In the end what did Bob decide to do?" A: Hired his brother over the other candidate, B: Hired the other candidate instead of his brother, C: Stayed with your company Galaxy, D: Switched to the competing company Helio, E: Kept quiet about the preliminary results, F: Released the preliminary results to the press, G: Stayed on your team, the Eagles, H: Switched to the opposing team, the Strikers.

Evaluation Items. Three items measured immorality, loyalty, and positivity towards the actor. First, participants were asked "In your opinion, how morally right or wrong were Bob's actions?" on a scale from 1: Not at all Immoral to 8: One of the most immoral things that can be done. Next they were asked to rate how loyal or disloyal Bob's actions were on a scale from 1: Not at all Disloyal to 8: One of the most disloyal things that can be done. Finally, they were asked "How do you feel about Bob?" on a scale of 1: Extremely Negative to 8: Extremely Positive (see Appendix B for a full listing of evaluation questions). 
Demographic Questionnaire. Finally, participants answered a brief survey about their sex, year of birth, race, ethnicity, primary country of citizenship, and primary country of residence.

\section{Study 2 Results}

Mean Morality Ratings. On average participants described the actions in question as being between very slightly immoral (2) and slightly immoral (3) $(M=2.25, S D=1.33)$. Actions in scenarios with stronger group ties were rated as more immoral $(M=2.44, S D=1.85)$ than the same actions in scenarios with weaker group ties $(M=2.06, S D=1.61)$. Also, immorality ratings were highest to lowest on average for the whistleblowing scenario $(M=2.70, S D=1.95)$ then the team scenario $(M=2.46, S D=1.81)$, then the defection scenario $(M=2.06, S D=1.57)$, and then the family scenario $(M=1.79, S D=1.47)$, see Figure 5. Overall, immortality ratings were quite low on average - all conditions less than 3 on a scale from $1=$ lowest to $8=$ highest. Inferential tests of these differences and the key hypothesis are presented in the mixed model next. 
Frazier 30

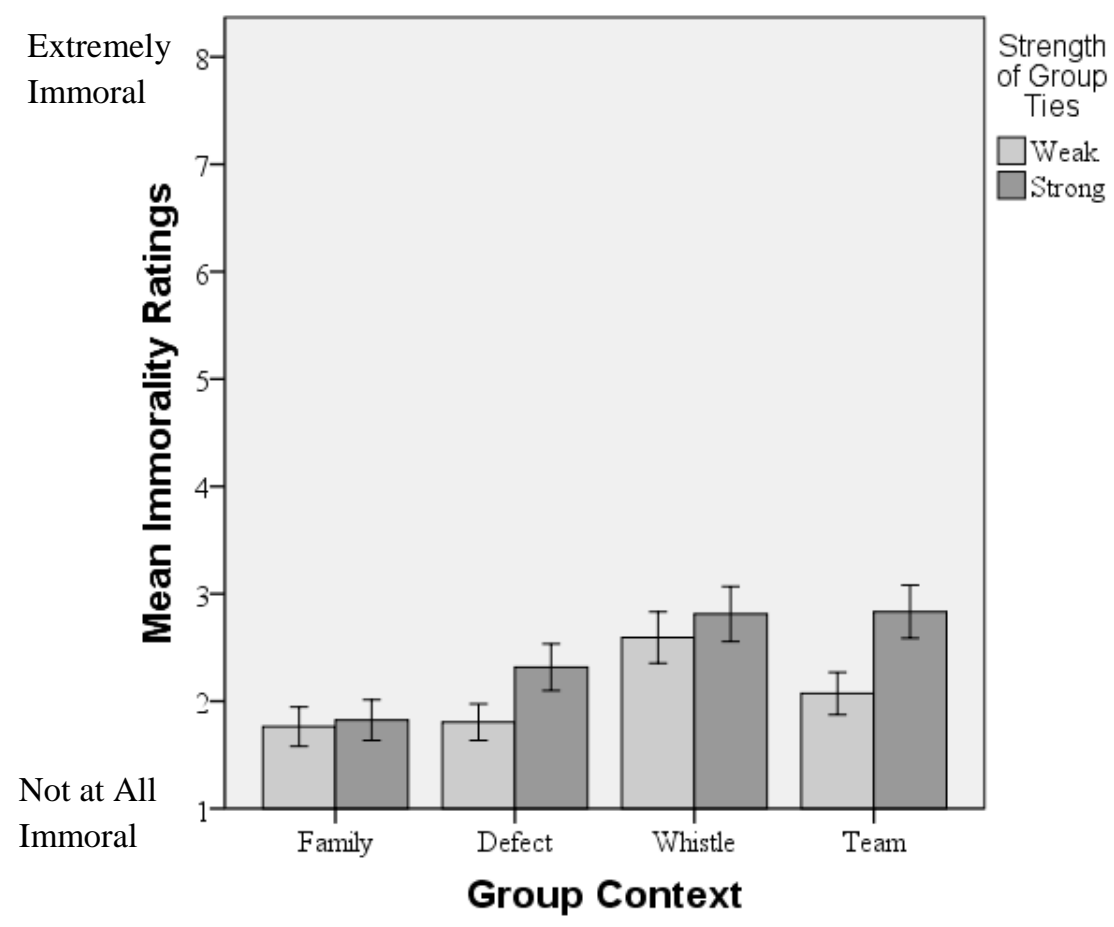

Figure 5. Mean Immorality Ratings by Scenario. Note: Error bars represent $95 \%$ confidence intervals.

Mixed Effects Modeling to Predict Morality Ratings. To test the effects of group ties and political ideology on morality ratings I ran a linear mixed effects model with a random slope of group nested within prompt using the lmer package in R. In this model I investigated three primary effects: (1) the fixed effect of group ties (strong/weak), (2) the fixed effect of individual social political ideology, ${ }^{6}$ and (3) the fixed effect of the interaction between social politics and group ties. I also included two random effects in the model (1) participant because group ties is manipulated within subjects, and (2) the effect of group ties nested within group context (to account for differences across the four group contexts). In the mixed effects model predicting

${ }^{6}$ Social politics was chosen as the primary predictor variable here as in Study 1a and 1b. Effects for the mixed model are very similar with overall politics as the predictor-group ties $X^{2}(1)=$ $7.32, p=0.007$, overall politics $X^{2}(1)=9.78, p=0.002$, and no statistically significant interaction $X^{2}(1)=0.46, p=0.50$. 
morality ratings, I found a significant effect of social politics $\left(\chi^{2}(1)=14.36, p=.0002\right)^{7}$ and of group ties $\left(\chi^{2}(1)=6.81, p=.009\right)$, but no interaction between social politics and group ties $\left(\chi^{2}(1)\right.$ $=0.03, p=.87$ ) (See Table 11 for the full model results). On average, conservatives rated the potentially disloyal actions as more immoral than liberals did, and actions with stronger group ties were rated as more immoral than actions with weaker group ties (see Figure 6).

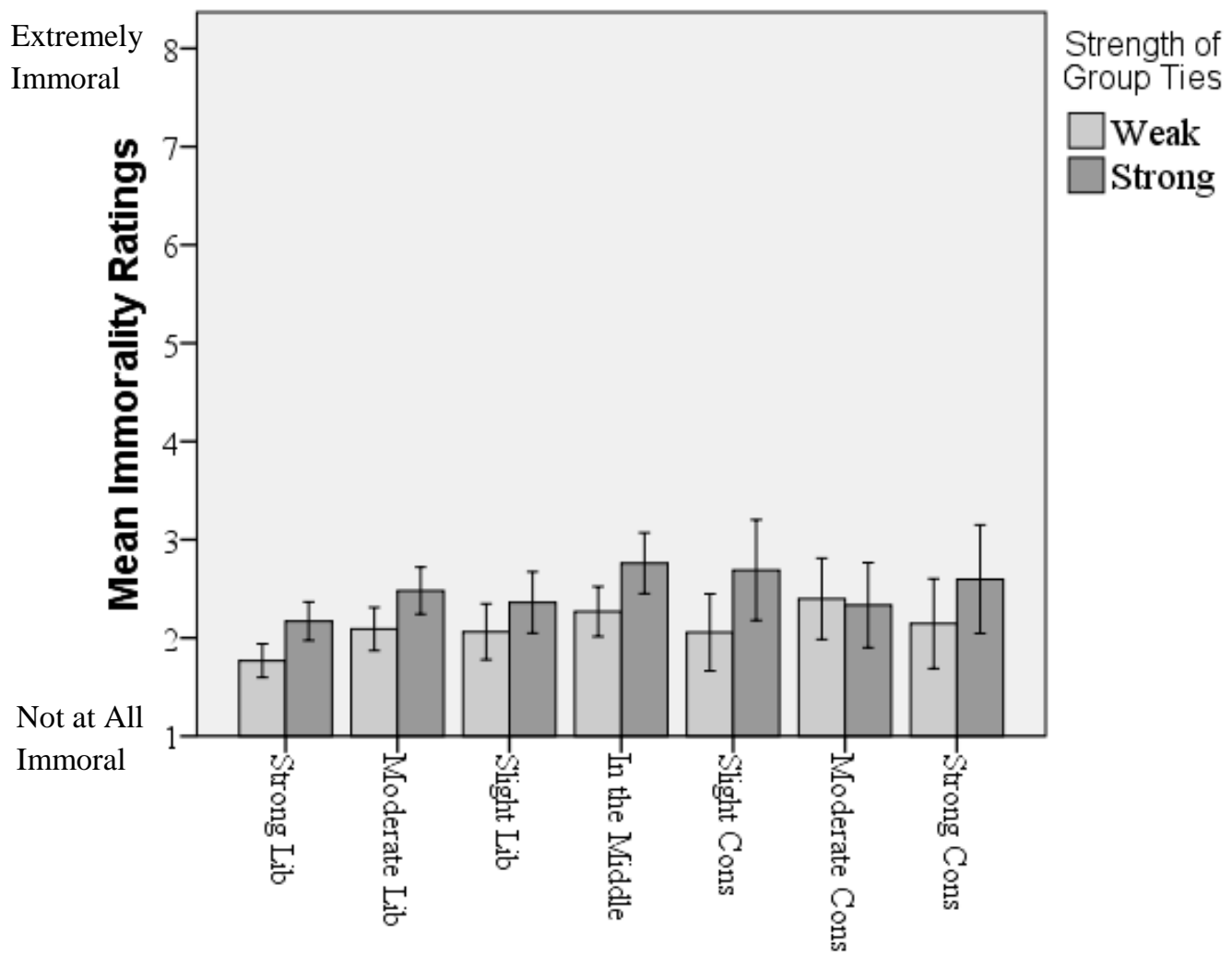

Social Politics

Figure 6. Mean Immorality Ratings by Social Politics and the Strength of Group Ties. Note:

Error bars represent $95 \%$ confidence intervals.

${ }^{7}$ Chi-squared values are based on Kenward-Roger F approximations, per Judd et al. 2012 which suggests using Type II Wald Chi-Squared Tests to conduct an Analysis of Deviance. 
Mean Loyalty Ratings. On average participants described the actions in question as being between slightly disloyal (3) and somewhat disloyal (4) $(M=3.84, S D=2.04)$. Actions in scenarios with stronger group ties were rated as more disloyal $(M=4.09, S D=2.05)$ than the same actions in scenarios with weaker group ties $(M=3.58, S D=1.99)$. Also, loyalty ratings were highest to lowest on average for the team scenario $(M=4.49, S D=1.87)$ then the whistleblowing scenario $(M=4.35, S D=1.98)$, then the defection scenario $(M=3.61, S D=$ 1.98), and then the family scenario $(M=2.92, S D=1.92)$, see Figure 7 . Overall, loyalty ratings were around the low-end to the middle of the scale on average - all conditions were between 2 and 5 on a scale from $1=$ lowest to $8=$ highest. Inferential tests of these differences and the key hypothesis are presented in the mixed model next.

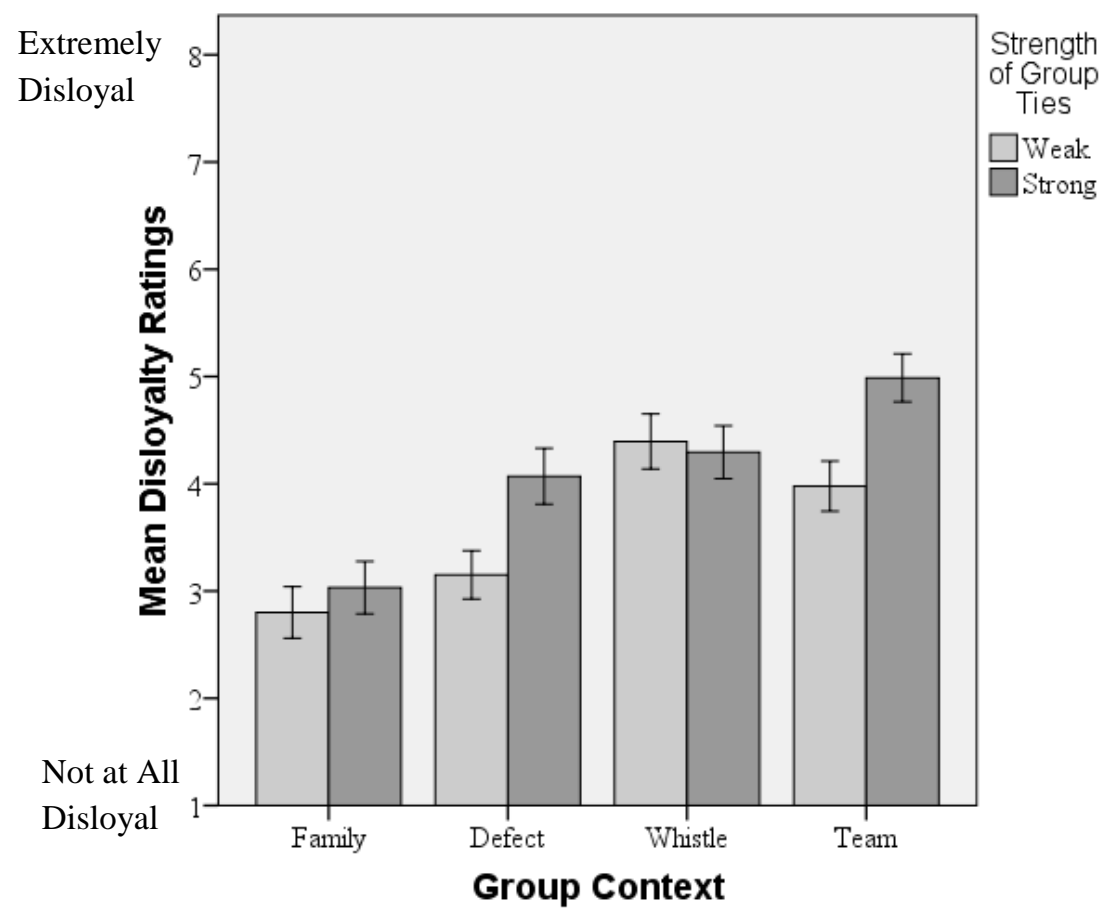

Figure 7. Mean Disloyal Ratings by Scenario. Note: Error bars represent $95 \%$ confidence intervals. 
Mixed Effects Modeling to Predict Loyalty Ratings. I then predicted loyalty ratings using the same model specifications as described in the morality mixed effects model above. In the mixed effects model predicting loyalty ratings $^{8}$, I found a significant effect of group ties $\left(\chi^{2}(1)=\right.$ $3.96, p=.05)$, but no effect of social politics $\left(\chi^{2}(1)=1.39, p=.24\right)$, and no interaction between social politics and group ties $\left(\chi^{2}(1)=0.27, p=.60\right)$, (See Table 12 for full model results). On average, actions with strong group ties were rated as more disloyal than actions with weaker group ties (see Figure 8).

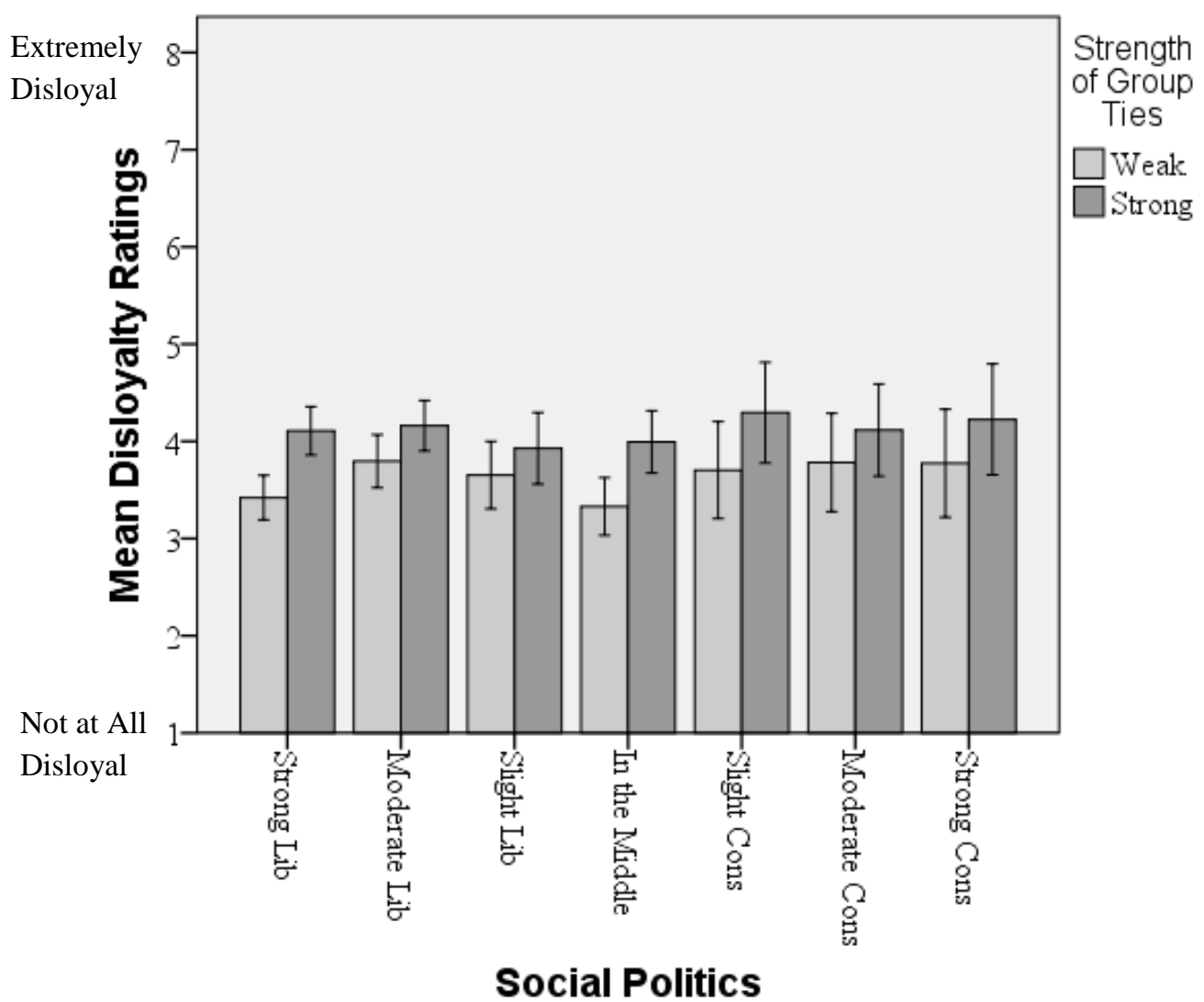

Figure 8. Mean Disloyal Ratings by Social Politics and Strength of Group Ties. Note: Error bars represent $95 \%$ confidence intervals.

\footnotetext{
${ }^{8}$ Effects for the mixed model for loyalty are very similar with overall politics as the predictorgroup ties $X^{2}(1)=4.00, p=0.05$, overall politics $X^{2}(1)=2.57, p=0.11$, and the interaction $X^{2}(1)$ $=0.03, p=0.86$.
} 
Mean Negativity Ratings. On average participants reported feeling slightly positive (4) about the actor $(M=3.98, S D=1.79)$. In scenarios with stronger group ties the actor was evaluated more negatively $(M=4.21, S D=1.85)$ than in scenarios with weaker group ties $(M=$ $3.75, S D=1.70)$. Also, negativity ratings were highest to lowest on average for the team scenario $(M=4.83, S D=1.49)$ then the defection scenario $(M=3.92, S D=1.768)$, then the whistleblowing scenario $(M=3.83, S D=1.91)$, and then the family scenario $(M=3.36, S D=$ 1.66), see Figure 9. Inferential tests of these differences and the key hypothesis are presented in the mixed model next.

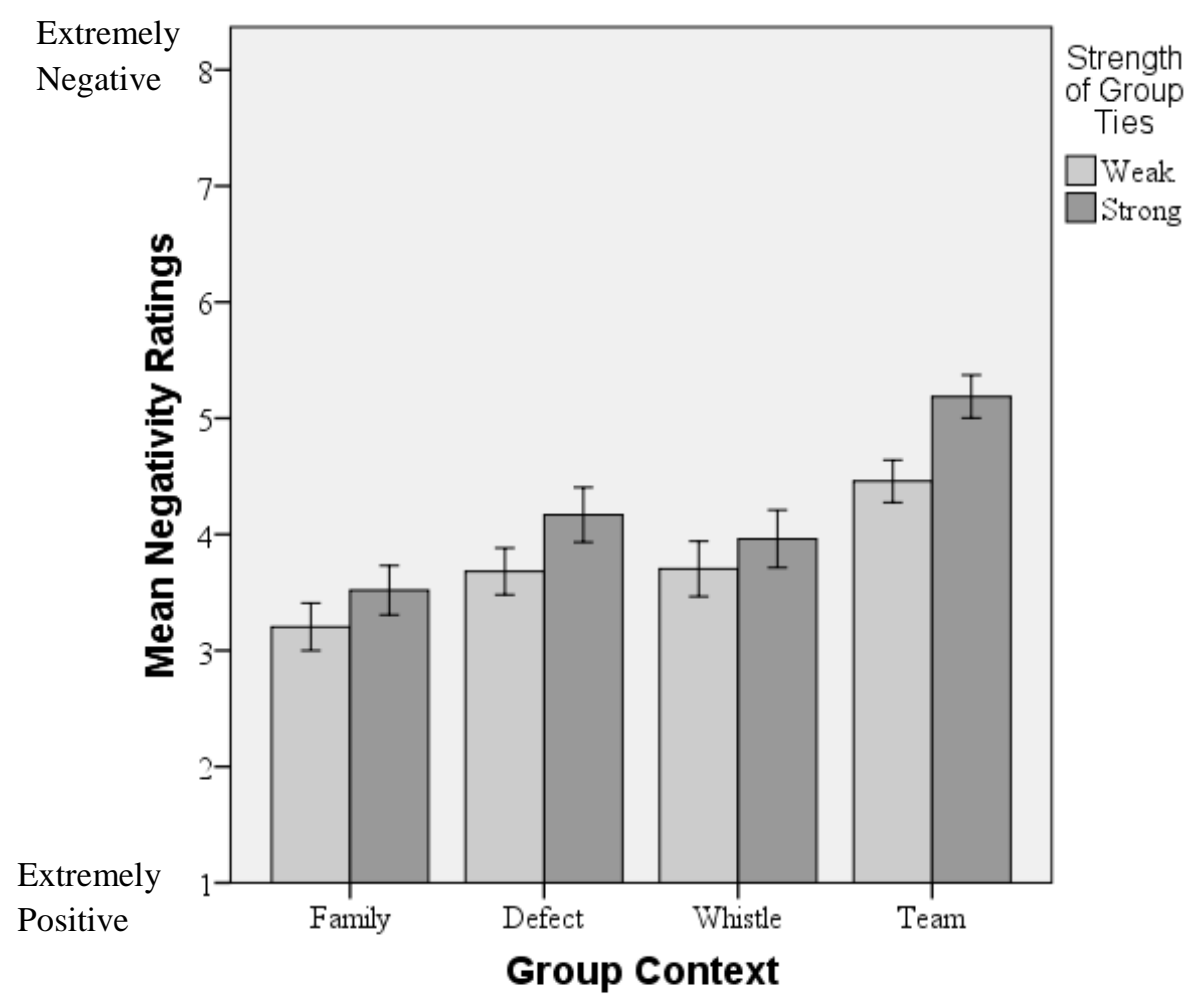

Figure 9. Mean Negativity Ratings by Scenario. Note: Error bars represent 95\% confidence intervals. 


\section{Mixed Effects Modeling to Predict Positivity Ratings. Finally, I predicted}

positivity/negativity ratings using the same model specifications as described in the morality mixed effects model above. In the mixed effects model predicting positivity ratings ${ }^{9}$, I found a significant effect of group ties $\left(\chi^{2}(1)=18.48, p<.00001\right)$, but no effect of social politics $\left(\chi^{2}(1)=\right.$ $.94, p=.33$ ) and no interaction between social politics and group ties $\left(\chi^{2}(1)=.29, p=.59\right)$ (See Table 13 for full results). On average, actions with strong group ties resulted in more negative feelings about the actor than actions with weak group ties (see Figure 10).

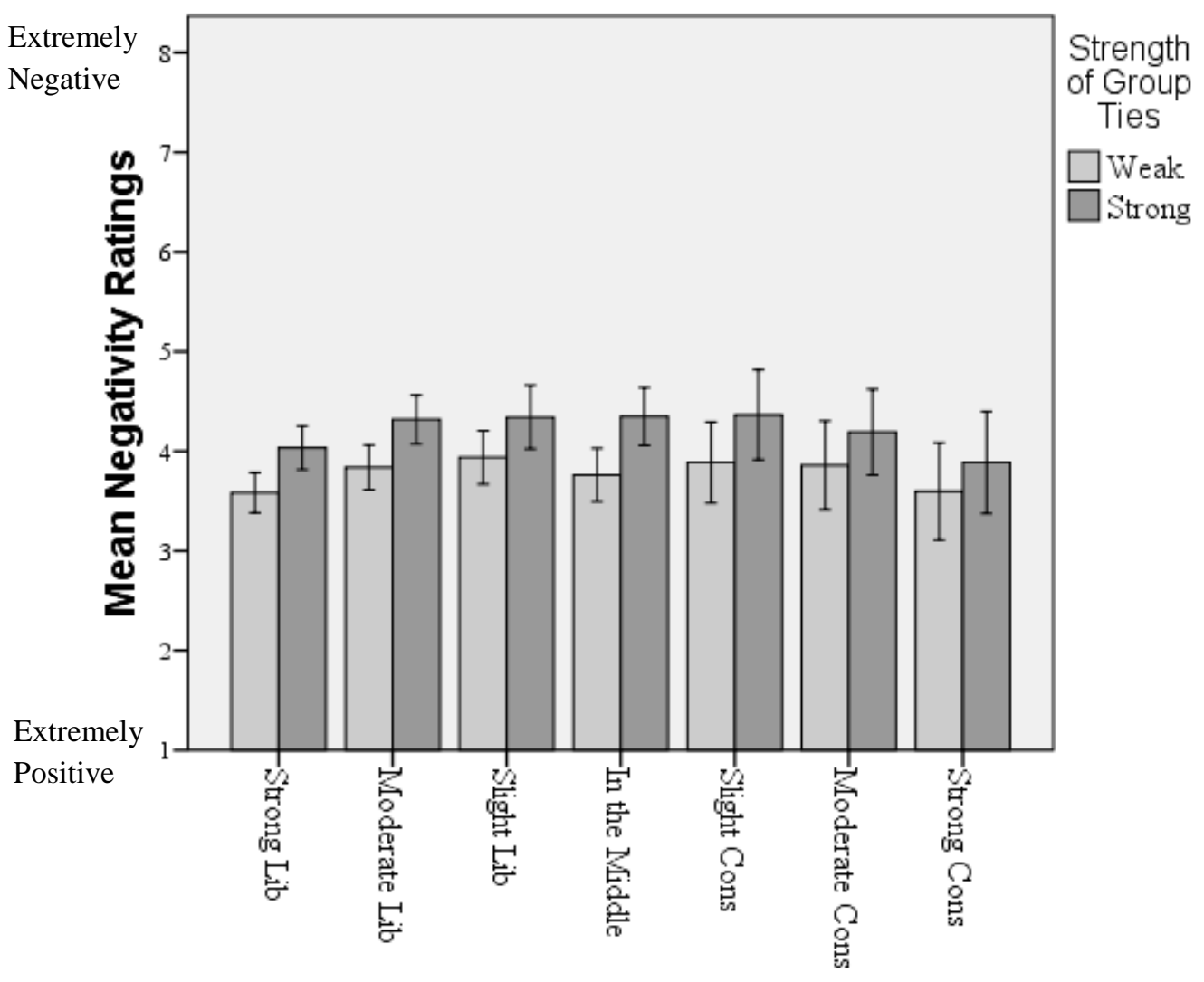

Social Politics

Figure 10. Mean Negativity Ratings by Social Politics and Strength of Group Ties. Note: Error bars represent $95 \%$ confidence intervals.

${ }^{9}$ Effects for the mixed model for positivity are very similar with overall politics as the predictor-group ties $X^{2}(1)=17.34, p=0.00003$, overall politics $X^{2}(1)=3.05, p=0.08$, and the interaction $X^{2}(1)=0.06, p=0.81$. 


\section{Discussion of Study 2 Results}

On average the scenarios were rated as disloyal by participants and these effects were amplified in the strong group ties condition—suggesting that the scenarios did indeed appear to be disloyal and the strength of group ties manipulation was successful. However, contrary to my predictions, while conservatives were more likely to rate the potentially disloyal actions as immoral, I found no significant differences between liberals and conservatives' loyalty or positivity ratings and no interactions between group ties and social politics.

Participants did not perceive the actions in the scenarios as particularly immoral and they did not feel negatively about the actors who committed the actions. Therefore, while the scenarios may represent disloyal actions, the presence of competing moral interests appears to have led participants to view the action as disloyal but not immoral. In other words, when there are moral justifications for the action chosen, actions that might otherwise be perceived as immoral (disloyalty) are not. In turn, this lack of severity may explain why the predicted interactions between ideology and group ties were not found. It may be that in order to see an interaction the action described in the scenario must be perceived as an immoral act because of disloyalty.

It is certainly possible that my expectation for an interaction between group ties and ideology is incorrect. However, I sought to test the possibility one more time by modifying my procedure to eliminate any other possible moral justifications for the disloyal action so that any differences between liberals and conservative's evaluations of the disloyal action/actor could only be attributed to the decision to disloyally prioritize individual interests over the group. 
Study 3

In Study 3, I removed any potential competing moral interests from each scenario and empirically investigated the whether political ideology and the strength of group ties interact to predict immorality and positivity ratings in situations where an individual has committed an action which is immoral because it is disloyal. In particular, in these revised scenarios the individual has clearly prioritized their own self-interest to the detriment of the group-- thus committing an action whose disloyalty is severe enough that it would be likely to be rated as immoral as well.

\section{Method}

\section{Participants}

Participants were 1,012 adults $^{10}\left(57.6 \%\right.$ female; $98.7 \%$ U.S. Citizens ${ }^{11}$, mean age $=35.1$ years old) directed to the study from Amazon's Mechanical Turk research website and paid twenty-five cents to participate in the approximately five minute study (overall completion time in seconds: $M=288.4, S D=137.5$ ) By political ideology, $52.3 \%$ of participants self-identified as liberal, $21.8 \%$ as conservative, and $25.9 \%$ as moderate.

\section{Procedure \& Materials}

The procedure for Study 3 was identical to that of Study 2, except for the updates to the scenarios themselves and the order of measures. The political identification and demographics measures were randomly ordered, and this pair was presented randomly before or after the scenarios, manipulation checks, and evaluation items.

\footnotetext{
${ }^{10}$ This number represents the final sample used for analysis after excluding participants who dropped out of the study prior to reaching the completion page necessary to receive mTurk credit $(\mathrm{N}=469$ ), participants who took greater than 20 minutes (which is $\sim 6.67 \mathrm{SD}$ above the mean) to complete the study $(\mathrm{N}=6)$, and participants who incorrectly answered more than one of the four manipulation check items $(\mathrm{N}=32)$.

${ }^{11}$ In order to be eligible for this study participants had to have indicated on their mTurk account that they were located in the United States.
} 
Moral Evaluation Scenarios. As in Study 2, participants read two short (1-2 paragraph) scenarios describing the potentially disloyal actions of a fellow group member. A total of eight different scenarios were used which varied both in terms of their group context and the strength of their group ties. The same group contexts were presented in Study 3 as in Study 2, but additional information was given about the rationale for the potentially disloyal action which made it appear more selfish and more immoral.

More specifically, in the family condition, your brother knows that your other brother really needs the job but chooses to not to hire your brother because he thinks his boss might not be pleased. In the defection condition, your coworker decides to use his knowledge of your company's business strategy to help get a job at the completion and help them to outperform your company. In the whistleblowing condition, your coworker convinces himself the final results of the study will be negative so he wants to be the one to release the preliminary results now even if it will hurt your company. Finally, in the team condition, you're on a professional soccer team and your teammate decides to switch to an opposing team right before the finals because he believes it would virtually guarantee that he would win the championship.

Each group context was also manipulated in terms of its group ties (either strong or weak) but the manipulations of group ties was the same as Study 2 (See Appendix C for a full listing of each of the eight moral evaluation scenarios).

\section{Study 3 Results}

Mean Morality Ratings. On average participants described the actions in question as being between slightly immoral (3) and somewhat immoral (4) $(M=3.07, S D=1.97)$. Actions in scenarios with stronger group ties were rated as immoral $(M=3.09, S D=1.99)$ as the same actions in scenarios with weaker group ties $(M=3.04, S D=1.94)$. Also, immorality ratings were 
highest to lowest on average for the whistleblowing scenario $(M=3.57, S D=2.10)$ then the team scenario $(M=3.38, S D=1.95)$, then the defection scenario $(M=3.09, S D=1.87)$, and then the family scenario $(M=2.26, S D=1.67)$, see Figure 11 . Overall, immortality ratings were higher than in Study 2, but still quite low on average - all conditions less than 4 on a scale from $1=$ lowest to $8=$ highest. Inferential tests of these differences and the key hypothesis are presented in the mixed model next.

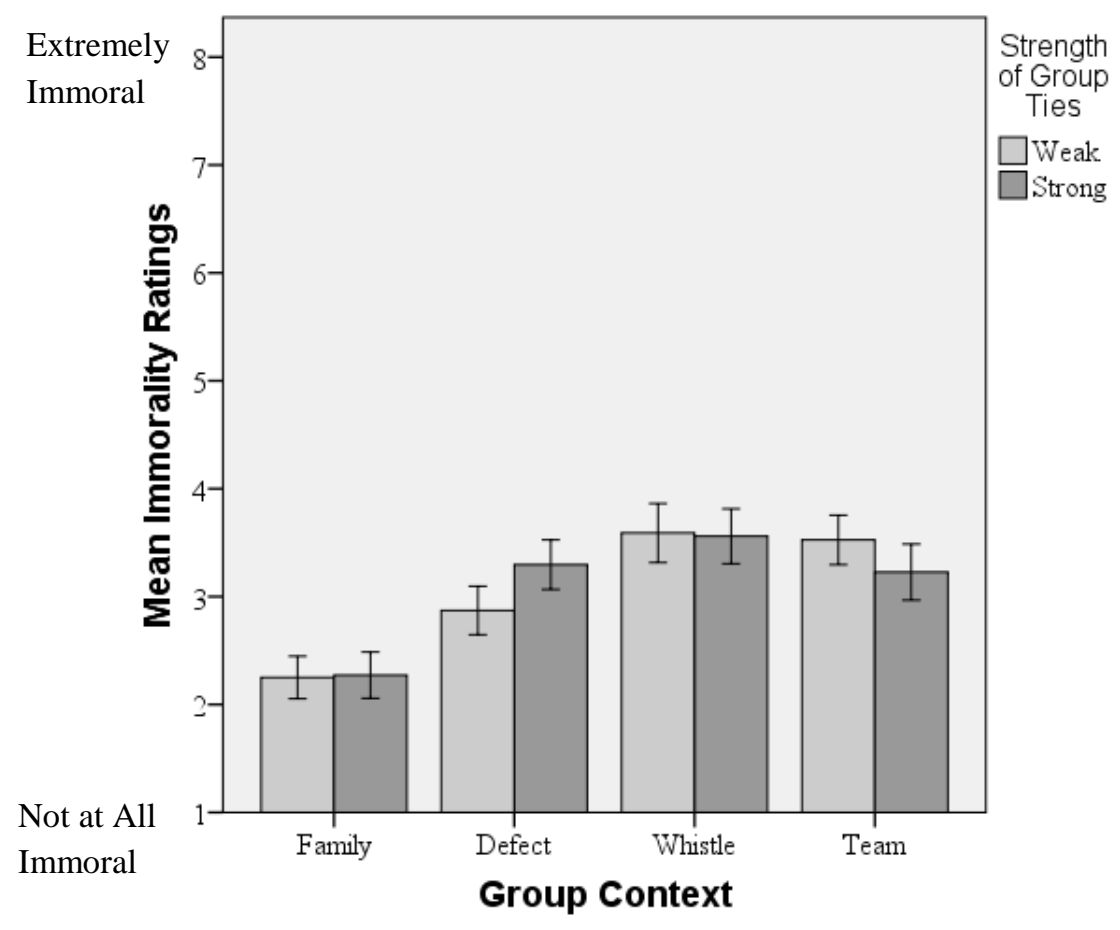

Figure 11. Mean Immorality Ratings by Scenario. Note: Error bars represent $95 \%$ confidence intervals.

Mixed Effects Modeling to Predict Morality Ratings. To test the effects of group ties and political ideology on morality ratings I ran a linear mixed effects model with a random slope of group nested within prompt using the lmer package in R. In this model I investigated three 
primary effects: (1) the fixed effect of group ties (strong/weak), (2) the fixed effect of individual social political ideology, ${ }^{12}$ and (3) the fixed effect of the interaction between social politics and group ties. I also included two random effects in the model (1) participant because group ties is manipulated within subjects, and (2) the effect of group ties nested within group context (to account for differences across the four group contexts). In the mixed effects model predicting morality ratings, I found a significant effect of social politics $\left(\chi^{2}(1)=11.28, p=.0007\right)^{13}$ but no effect of group ties $\left(\chi^{2}(1)=0.04, p=.84\right)$, and no interaction between social politics and group ties $\left(\chi^{2}(1)=1.14, p=.29\right)$ (See Table 14 for the full model results). On average, conservatives rated the potentially disloyal actions as more immoral than liberals did, and actions with stronger group ties were rated as more immoral than actions with weaker group ties (see Figure 12).

${ }^{12}$ Social politics was chosen as the primary predictor variable here as in Study 1a and 1b. Effects for the mixed model are similar with overall politics as the predictor- group ties $X^{2}(1)=0.04, p$ $=0.84$, overall politics $X^{2}(1)=3.42, p=0.06$, and the interaction $X^{2}(1)=1.27, p=0.26$.

${ }^{13}$ Chi-squared values are based on Kenward-Roger F approximations, per Judd et al. 2012 which suggests using Type II Wald Chi-Squared Tests to conduct an Analysis of Deviance. 


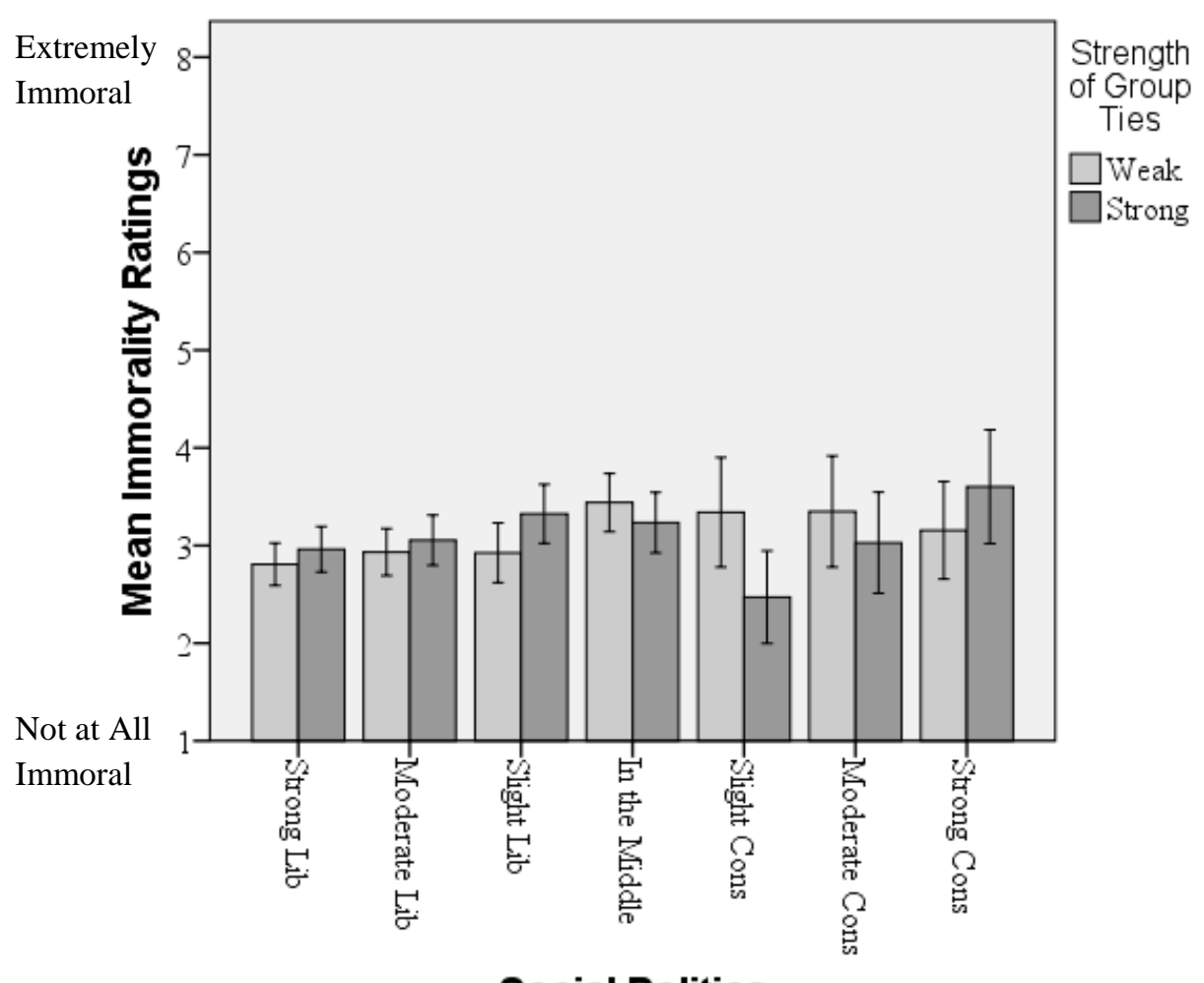

Social Politics

Figure 12. Mean Immorality Ratings by Social Politics and the Strength of Group Ties. Note: Error bars represent $95 \%$ confidence intervals.

Mean Loyalty Ratings. On average participants described the actions in question as being between somewhat disloyal (4) and Moderately Disloyal (5) $(M=4.63, S D=2.02)$. Actions in scenarios with stronger group ties were rated as slightly more disloyal $(M=4.73, S D=2.02)$ than the same actions in scenarios with weaker group ties $(M=4.53, S D=2.03)$. Also, loyalty ratings were highest to lowest on average for the team scenario $(M=5.45, S D=1.79)$ then the whistleblowing scenario $(M=4.91, S D=1.96)$, then the defection scenario $(M=4.61, S D=$ $1.95)$, and then the family scenario $(M=3.62, S D=1.94)$, see Figure 13 . Overall, loyalty ratings were around the middle of the scale on average - all conditions were between 3 and 6 on a scale from $1=$ lowest to $8=$ highest. Inferential tests of these differences and the key hypothesis are presented in the mixed model next. 


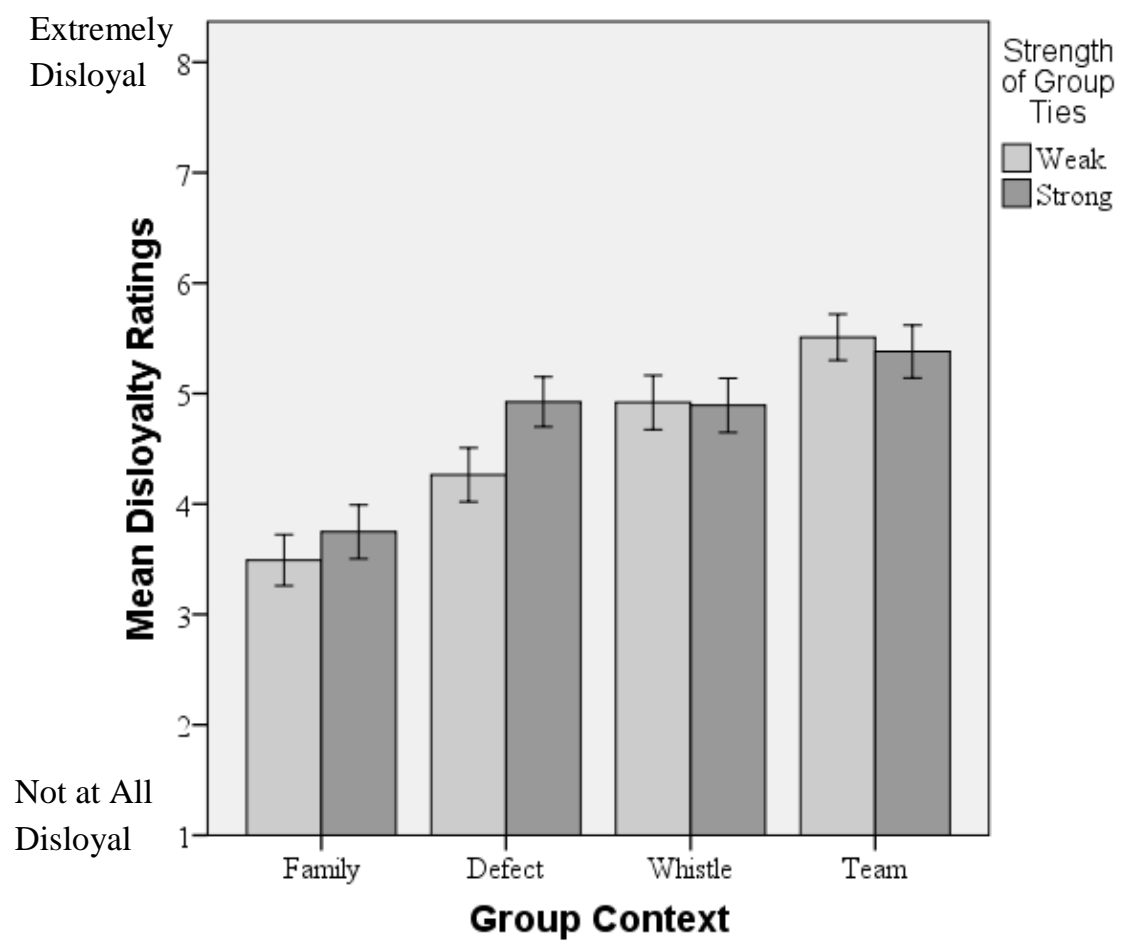

Figure 13. Mean Disloyalty Ratings by Scenario. Note: Error bars represent $95 \%$ confidence intervals.

Mixed Effects Modeling to Predict Loyalty Ratings. I then predicted loyalty ratings using the same model specifications as described in the morality mixed effects model above. In the mixed effects model predicting loyalty ratings ${ }^{14}$, I did not find a significant main effect of group ties $\left(\chi^{2}(1)=1.25, p=.26\right)$, or social politics $\left(\chi^{2}(1)=0.02, p=.89\right)$, nor an interaction between social politics and group ties $\left(\chi^{2}(1)=3.06, p=.08\right)$, (See Figure 14; also see Table 15 for full model results).

${ }^{14}$ Effects for the mixed model for loyalty with overall politics as the predictor-group ties $X^{2}(1)$ $=1.26, p=0.26$, overall politics $X^{2}(1)=0.86, p=0.35$, and the interaction $X^{2}(1)=0.76, p=0.38$. 
Frazier 43

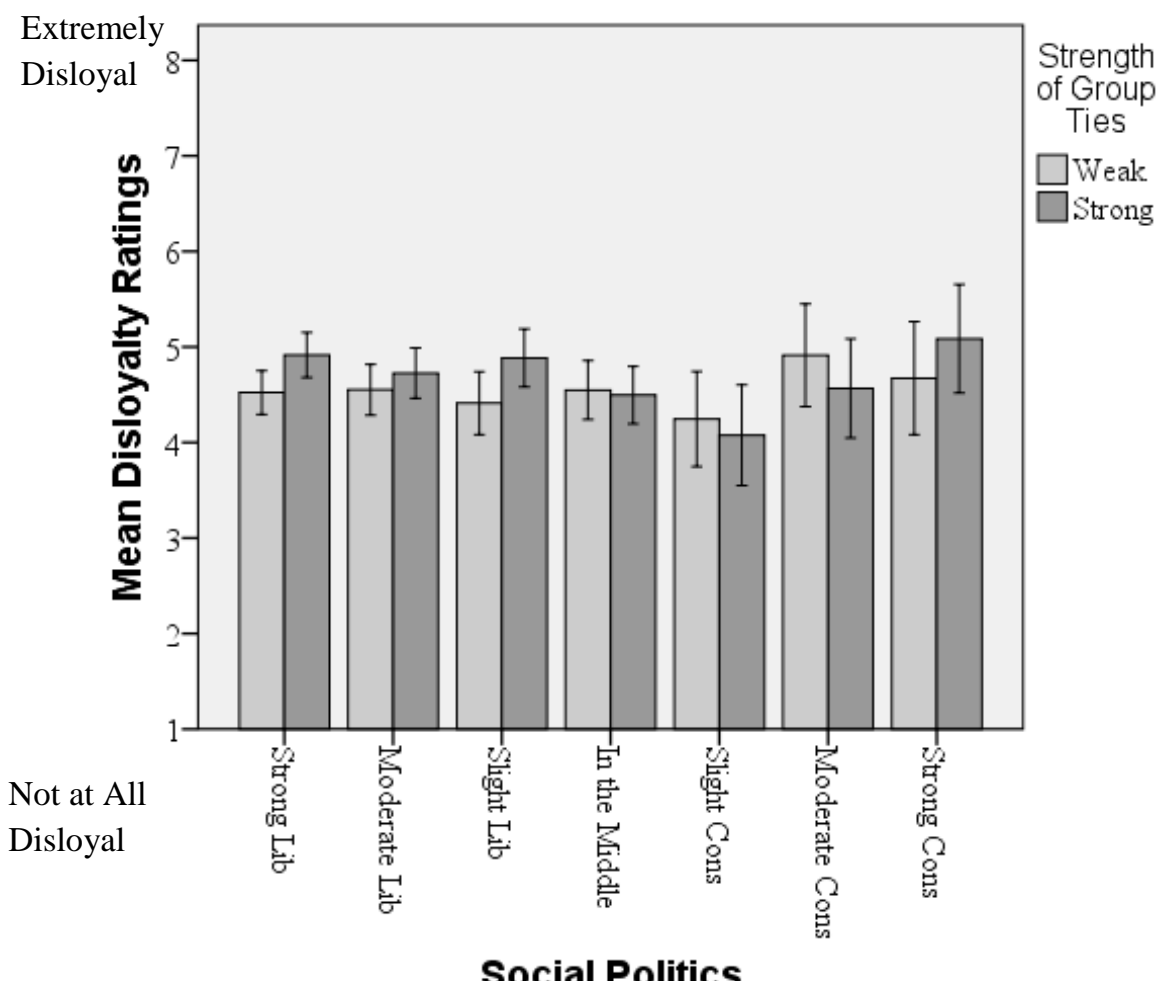

Social Politics

Figure 14. Mean Disloyalty Ratings by Social Politics and the Strength of Group Ties. Note:

Error bars represent $95 \%$ confidence intervals.

Mean Negativity Ratings. On average participants reported feeling slightly negative (5) about the actor $(M=5.03, S D=1.61)$. In scenarios with stronger group ties the actor was evaluated just as negatively $(M=5.05, S D=1.64)$ as in scenarios with weaker group ties $(M=$ $5.01, S D=1.60)$. Also, negativity ratings were highest to lowest on average for the team scenario $(M=5.58, S D=1.38)$ then the defection scenario $(M=5.16, S D=1.46)$, then the whistleblowing scenario $(M=5.05, S D=1.82)$, and then the family scenario $(M=4.35, S D=$ 1.53), see Figure 15. Inferential tests of these differences and the key hypothesis are presented in the mixed model next. 


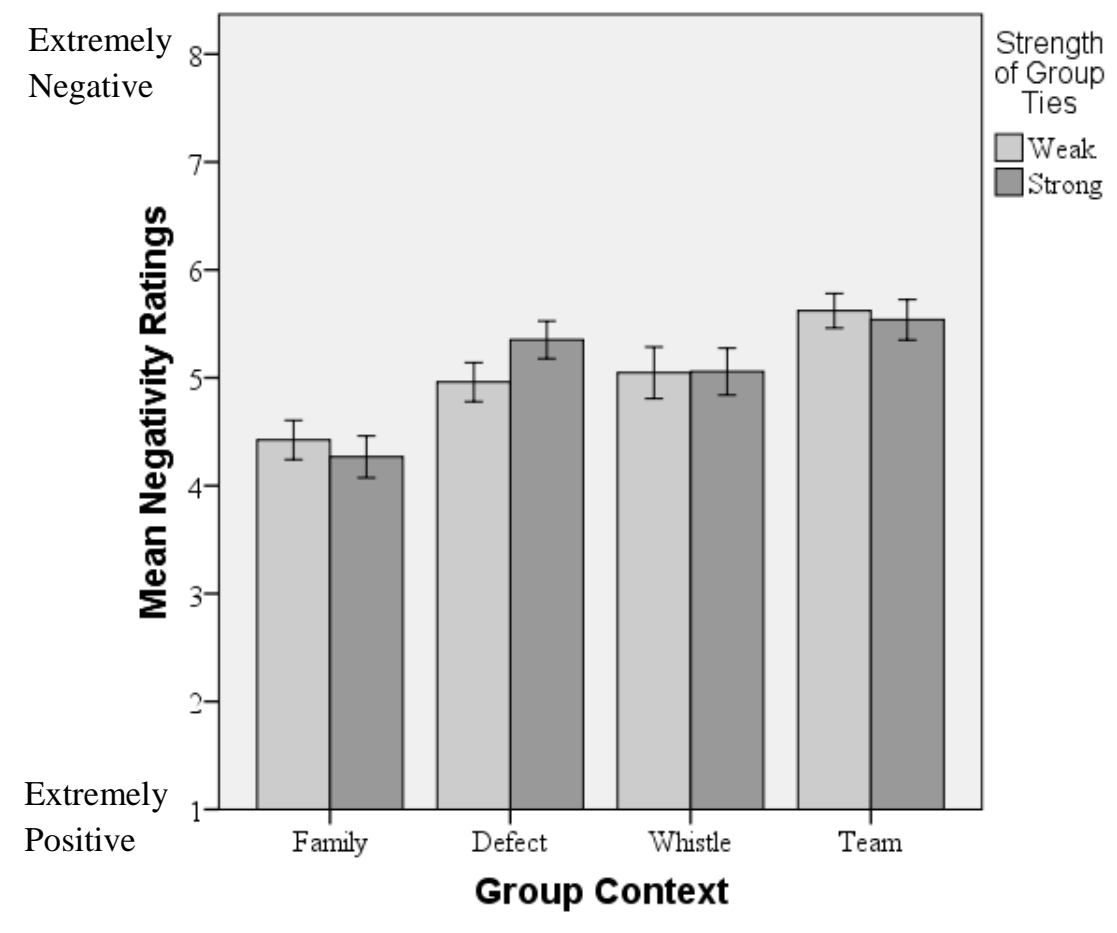

Figure 15. Mean Negativity Ratings by Scenario. Note: Error bars represent $95 \%$ confidence intervals.

Mixed Effects Modeling to Predict Positivity Ratings. Finally, I predicted positivity/negativity ratings using the same model specifications as described in the morality mixed effects model above. In the mixed effects model predicting positivity ratings ${ }^{15}$, I did not find a significant effect of group ties $\left(\chi^{2}(1)=0.16, p=0.69\right)$, or of social politics $\left(\chi^{2}(1)=1.68, p\right.$ $=.20)$ or the interaction between social politics and group ties $\left(\chi^{2}(1)=.79, p=0.37\right)$ (See Figure 16; see also Table 16 for full model results).

${ }^{15}$ Effects for the mixed model for positivity with overall politics as the predictor- group ties $X^{2}(1)=0.16, p=0.69$, overall politics $X^{2}(1)=2.99, p=0.08$, and the interaction $X^{2}(1)=0.95, p$ $=0.33$. 
Frazier 45

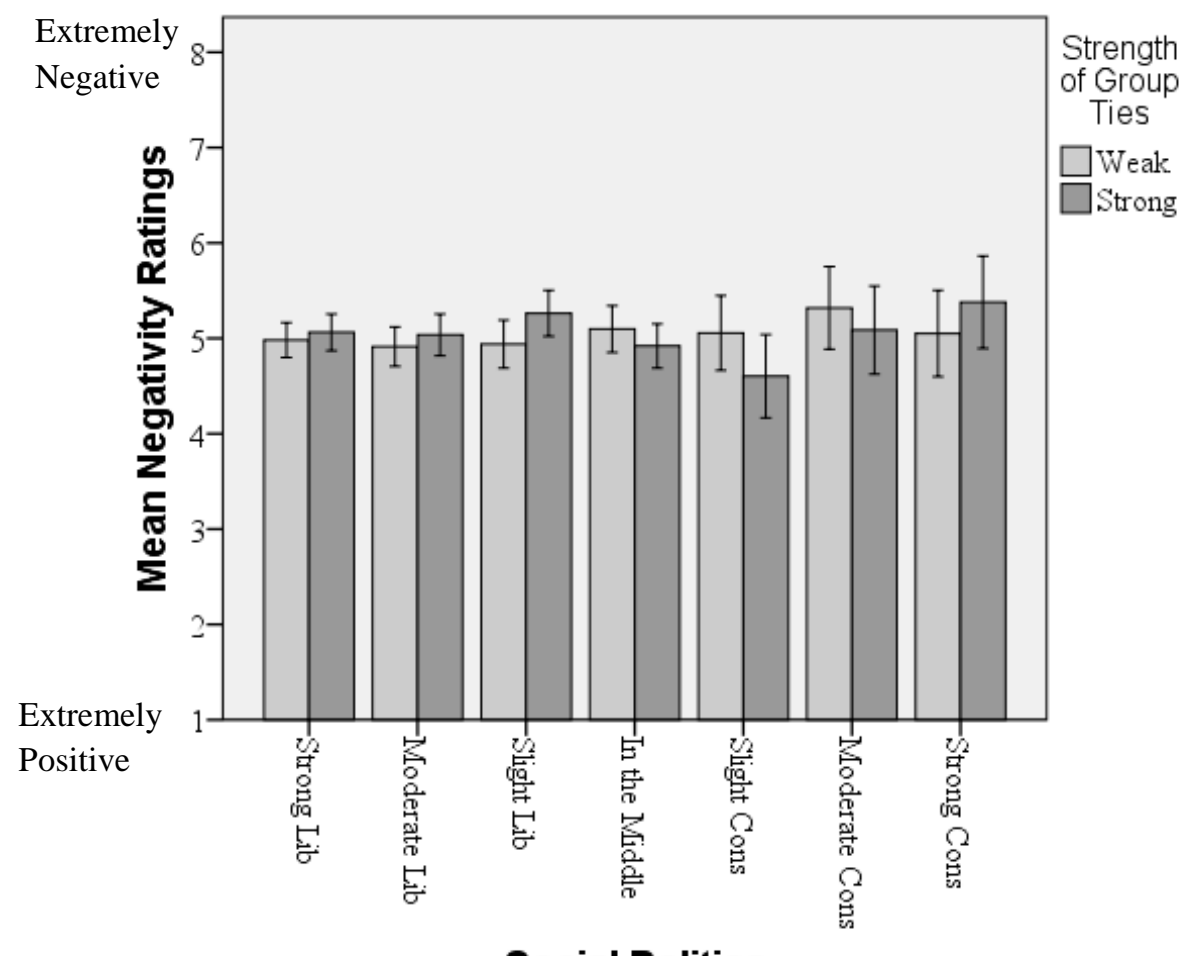

Social Politics

Figure 16. Mean Negativity Ratings by Social Politics and the Strength of Group Ties.

Note: Error bars represent $95 \%$ confidence intervals.

\section{Discussion of Study 3 Results}

In Study 3, on average the scenarios were rated as more immoral, more disloyal, and the actors were evaluated more negatively than in Study 2. This suggests that I was able to increase the extent of moral concerns triggered in the scenarios and that on average the scenarios were now rated as both immoral and disloyal as intended. However, this increase in overall ratings was accompanied by a decrease in the difference between scenarios with strong and weak group ties. While Study 2 had found that participants were more likely to rate actions as immoral in the context of strong group ties, in Study 3 there was no statistically significant difference based on the strength of group ties. On the other hand, however, I did replicate the findings from Study 2 showing that conservatives were once again more likely to rate the potentially disloyal actions as 
immoral but not disloyal or negative. Finally, for the fourth study in a row, I did not find evidence to support the hypothesized interaction between ideology and group ties. This suggests that liberals and conservatives may not have been differentially affected by the strength of group ties information.

After Study 2, I had predicted that in order to see an interaction the action described in the scenario must be perceived as an immoral act because of disloyalty. However, in Study 3, I was able to establish a scenario which participants viewed as both disloyal and immoral. However, the proposed interactions between ideology and group ties did not occur.

\section{General Discussion}

Moral Foundations Theory suggests that conservatives place a higher moral value on ingroup loyalty than their liberal counterparts (Haidt \& Graham, 2007). This prediction was weakly supported in studies 2 and 3. But I also predicted that conservatives should be more likely to demonstrate amplified moral concerns about loyalty when ties to the group are particularly strong (Haidt, 2012). However, across four studies and almost 9,000 participants, I failed to find evidence to support the hypothesis that political ideology interacts with the strength of group ties to predict loyalty behaviors and evaluations. While it is possible that the proposed interaction may exist and was simply not observed within the current studies, given that the studies performed were adequately powered and the null effects were observed across a wide range of dependent measures (giving in a public goods task, cooperating in the prisoners dilemma task, and evaluations of the immorality, disloyalty, and negativity of an ingroup member) I must also consider the possibility that the proposed interaction may not exist or may be much smaller than previously thought. As such, the current results could be explained by 
three distinct possibilities: (1) that individuals' values may not predict their actual behaviors and evaluations of others, (2) that the effects of political ideology may be smaller than previously thought, or (3) the current measures are not able to adequately capture the interaction as it operates in real life.

\section{Why isn't there an interaction between ideology and group ties?}

Possibility \#1: Values do not always predict behavior. Evidence for Moral Foundations Theory suggests that conservatives view ingroup loyalty as highly relevant to their moral values and to their judgments about moral behaviors (Graham, Nosek, Haidt, Iyer, Koleva, \& Ditto, 2011; Haidt \& Graham, 2007). However, it is also well-known that values and attitudes do not always predict behavior (Azjen \& Fishbein, 2005; also see Graham, Meindl, Koleva, Iyer, \& Johnson, In Press, for a review of when moral values fail to predict moral behaviors). As such, it's possible that the values that individuals claim are important to them are not predictive of their behavior in complex situations such as social dilemmas and social evaluations. For example, conservatives may discuss loyalty as a moral virtue more than liberals (Graham, Haidt, $\&$ Nosek, 2009) and may say that they support hierarchical structures that put their group ahead of other groups (Pratto, Sidanius, Stallworth, \& Malle, 1994; Sidanius \& Pratto, 1999). However, these values may not mean that they are more likely to display loyalty while interacting with friends than with anonymous others, or that they are more likely to negatively evaluate disloyal group members when they have strong ties to the group.

Possibility \#2: Political ideology effects may be much smaller than previously thought. The Moral Foundations Questionnaire consistently shows ideological differences in the abstract valuing of ingroup loyalty. However, these differences are relatively small in magnitude — with 
average ratings of the moral relevance of ingroup loyalty ranging from slightly relevant to somewhat relevant (Haidt \& Graham, 2007; Graham, Nosek, Haidt, Iyer, Koleva, \& Ditto, 2011). I replicated this effect in Study 1a and 1b. However, the relatively small size of these effects on the abstract valuing of loyalty, might anticipate that the effects of ideology are even smaller in practice. Indeed, the results of this paper suggest that ideological differences do not predict how individuals interact with and evaluate others as a function of their ties to the group.

Additionally, it's possible that the proposed differences between liberals and conservatives with regard to ingroup loyalty are much smaller than I have assumed. A growing body of research suggests that differences in the values of liberals and conservatives may be exaggerated by members of the general population and that these stereotypes may lead individuals to overestimate the magnitude of the actual differences in moral values (Schere, Windschitl, \& Graham, In Press; Graham, Nosek, \& Haidt, 2012; Chambers, Baron, \& Inman, 2006). As such, it's possible that while small value differences may exist on self-report measures, the impact of these differences on behavior and evaluations may have been overestimated. The most dissatisfying aspect of this explanation is that there is essentially no evidence at all for the interaction of politics and group ties with almost 9,000 participants total. This leads to some doubt that it is a matter of the effects just being rather small.

Possibility \#3: Current measures may not capture the interaction. The current studies do present strong evidence in support of the null, however it's possible that these effects may be a function of how I have chosen to operationalize loyalty. If I had operationalized the variables differently, I may have found support for the key hypothesis.

In Study 1a/1b I operationalized loyalty as altruism towards the group at some cost to the self, in Study 2 and 3 I operationalized disloyalty as prioritizing the interests of the self at some 
cost to the group. In Study 1, it's possible that while ideology and group ties do not interact to predict giving in a public goods dilemma or cooperating in a prisoner's dilemma task these measures may not adequately capture the full range of loyalty decisions in the real world. In particular, Graham (2013) has commented that much of the work on economic games lacks the external validity necessary to study moral decision-making as it operates in the real world. For example, displaying loyalty may not always involve a cost to the self (as the current social dilemmas require), and so it's possible that perhaps we would see interactions between ideology and group ties if loyal behaviors did not involve penalizing the self.

Additionally, it's possible that these evaluation scenarios were not realistic enough to simulate the actual moral decision-making processes that happen in real life. The studies presented here involve social judgments and behavioral intentions when interacting with hypothetical online groups and it's possible that these artificial group settings may not be sufficient find differences which may actually exist. For example. Yamagishi's (2003) work on cross-cultural differences has shown that when subjects are asked to participate in artificially created groups the well-established collectivism-individualism differences between Japanese and American participants disappear. A similar phenomenon may be happening with liberals and conservatives as they participate in the current study. It may be that as participants read the hypothetical group scenarios online they were able to distance themselves from the group at hand. This distancing may have allowed them to avoid experiencing the high degree of moral affect that usually accompanies a betrayal. In real life individuals are not always able to distance themselves from the group and thus may have to rely more on ideology and information about group ties to make moral judgments. 
As such, it would be helpful for future research to explore the interaction between ideology and group ties in real world scenarios. While I haven't observed individual differences impacting behavioral intentions or hypothetical social interactions these differences may manifest themselves when individuals' ideologies are salient and they are interacting with groups that are meaningful to them. For example, it would be interesting to see if we would observe the proposed interaction if subjects were recruited from their existing groups (for example fraternities and sororities), primed with their political ideology, and then asked evaluate the disloyal actions of ingroup and outgroup members. Another component of meaningful group interaction is the establishment of group rules, norms, and institutions and so it would be useful for future research to explore whether conservatives' greater preference for hierarchy and constrained view of human nature (Sidanius \& Pratto, 1999; Sowell, 2002) leads them to place a higher value on loyalty (and greater punishments for disloyalty) when building institutions. For example, I would predict that conservatives might be especially likely to support rules and norms which encourage loyalty and punish betrayal of the group when establishing rules for real organizations to which they have strong group ties.

Of course, it is easy to hold on to a favored hypothesis by continuously discrediting prior studies as failed tests. However, each of the three studies in this dissertation were designed as the best possible tests of the interaction hypothesis with what I knew at the time. Study 2 was designed in response to the lack of effect in Study 1 with the thought that ideological differences might be more likely to predict evaluations of the disloyal behaviors of others than one's own behavior. Study 3 was designed in response to the lack of effect in Study 2 with the thought that the effects might be observed by ensuring that each scenario was immoral strictly because of its disloyalty. However, the continued null results across each of these studies suggests I need to 
take seriously the evidence that my hypothesis, to the extent that it operates under any

conditions, operates under a much more constrained set of conditions than I thought previously. And, these constraints have not yet been identified.

\section{Why are there weak and inconsistent main effects of ideology?}

In addition to the lack of evidence for an interaction between ideology and group ties, the current studies also present only very weak evidence for the main effects of ideology on loyalty behaviors and evaluations. In Study $1 \mathrm{a} \& 1 \mathrm{~b}$, there were slight main effects of ideology on social decision making showing that liberals were more cooperative than conservatives in the public goods game in Study 1 and $1 \mathrm{~b}$ and in the prisoner's dilemma game in Study 1b. However, these effect sizes were very small (accounting for less $1 \%$ of the overall variation in behavior). Furthermore, in Study 2, I found weak effects in the opposite direction for immorality ratings-such that conservatives rated the ambiguously disloyal behaviors as more immoral than liberals, but this effect was not found for loyalty or negativity ratings or for any of the evaluations in Study 3. These findings contradict my initial prediction that conservatives would be more loyal in their cooperative behaviors and more harsh in their evaluations of disloyal others, but they may provide weak evidence for the possibility that ideology has unique effects on loyalty displays in comparison to loyalty evaluations.

Ideology and Cooperation. In particular, the findings from Study 1 suggest that liberals may be slightly more likely to cooperate with others and act in the interests of their groups than conservatives-- regardless of their ties to the group. This finding is very much in line with the existing work on social value orientation which has shown that liberals are typically higher in prosocial value orientation than conservatives (Van Lange et al., 2012; Van Lange, Bekkers, Chirumbolo, \& Leone, 2012; Sheldon \& Nichols, 2009) and that higher levels of SVO are 
correlated with increased giving in tasks such as the public goods dilemma and prisoners dilemma game (Kollock, 1998; McClintock \& Van Avermaet, 1982). Indeed we replicate these findings in Study 1a and 1b in which we find that liberals are higher in SVO and that higher levels of SVO are associated with increased cooperation across both tasks.

However, my initial prediction that these differences were due to the weak group ties in the traditional SVO paradigm was not supported within the current studies. Instead, liberals were slightly more likely to cooperate than conservatives, even when interacting with close friends. This may suggest that although conservatives may value loyalty more, liberals' greater desire to help others (Rathbun, 2007) may overwhelm any potential interactions between group ties and ideology.

Ideology and Social Evaluation. On the other hand, loyalty behaviors and evaluations of the loyalty behaviors of others may not operate in the same way. Recent work on moral hypocrisy has shown that individuals often have different standards for their own moral behavior and the behavior of others. In general people to tend to make more positive attributions for their own moral misdeeds than those of others (Valdesolo and DeSteno, 2007; Kruger \& Gilovich, 2004; Valdesolo \& DeSteno, 2008) and are more attuned to the immoral deeds of others than themselves (Hofmann, Wisneski, Brandt, \& Skitka, 2014). As such, it's entirely possible that concerns about displaying loyalty oneself may be distinct from concerns about the disloyalty of others.

Study 2 and 3 suggest that when individuals are asked to evaluate the morality of an ingroup member who has committed a potentially disloyal action conservatives view this action as more immoral than liberals (regardless of the strength of their ties to the group). While liberals and conservatives were equally likely to view an action as disloyal and to negatively evaluate the 
actor, conservatives were slightly less likely to view the action itself as immoral. This might suggest that while liberals are more likely to display loyalty by cooperating with members of their group, they are slightly less likely to view disloyal actions within the group as immoral. These findings fit well with existing research on Moral Foundations Theory (Haidt \& Graham, 2005) and social dominance orientation (Sidanius \& Pratto, 1999) because they suggest conservatives greater valuing of ingroup loyalty and the dominance of the ingroup may lead them to view disloyal actions as more immoral than liberals do. This seems logical given that conservatives have been shown to have a greater desire to build and maintain group hierarchies (Jost, Glaser, Kruglanski, \& Sulloway, 2003) and thus should be particularly interested in labeling disloyal actions as immoral. Together, these findings may suggest that conservatives' higher valuing of ingroup loyalty is primarily focused on the enforcement of ingroup loyalty in others and a heightened sensitivity to betrayal, rather than displays of loyalty in the form of cooperative behavior.

\section{Why do we find consistent effects of group ties?}

In Study 1a/1b and Study 2 of my dissertation I found strong evidence that there is a main

effect of group ties on one's own loyalty behaviors and on evaluations of the loyalty behaviors of others. These findings are very much in line with existing work on ingroup favoritism (Tajfel \& Turner, 1979; Tajfel \& Billig, 1974; Brewer \& Karmer, 1985; Hogg \& Sunderland, 1991) and suggest that regardless of ideology, individuals are more likely to display prosocial behaviors towards fellow ingroup members than outgroup members (Brewer, 1979; Wilder, 1981). Furthermore, people tend to judge the moral transgressions of outgroup members more harshly than those of ingroup members (Valdesolo \& DeSteno, 2007) as we saw in Study 2. Overall 
these results suggest that group ties do seem to matter for who we cooperate with (we cooperate more with those we have strong group ties with) and how we evaluate others (we evaluate disloyal others more negatively when we have strong ties to the group) and the lack of an interaction suggests that these ties seem to matter equally to both liberals and conservatives

However, in Study 3, we did not find evidence that the strength of group ties impacts evaluations of the disloyal actions of others in situations where the action is very clearly disloyal. These findings suggest that the strength of group ties may be especially influential in situations in which the disloyalty of the action is ambiguous. It may be that there is a threshold for judgments of disloyalty and that when an action is ambiguously disloyal (as in Study 2) information about the history of group and the strength of your ties to the group may be especially influential for determining whether or not an action is disloyal. However, when this information is unambiguously presented additional information about the strength of group ties may not matter above and beyond the information about the betrayal itself.

\section{So what does it all mean?}

All in all the findings of this dissertation suggest that group ties do seem to matter for loyalty behavior and evaluation, but that ideology may not be as large a predictor of these outcomes as has been previously thought. Furthermore, the effects of group ties may be larger than originally anticipated. While future research may still be needed to explore the possible interaction between ideology and group ties in real world settings, the current studies suggest group ties matter to both liberals and conservatives equally and thus moral foundations theory should consider that the proposed interactive effects of ideology and group ties on loyalty behaviors and evaluations may be much smaller than previously suggested or may not exist at all. 


\section{References}

Abramotiwz, A. (2012). Forcasting in a polarized era: The time for change model and the 2012 presidential election. PS: Political Science \& Politics, 45(4), 618-619.

Ajzen, I., \& Fishbein, M. (2005). The influence of attitudes on behavior. In D. Albarracin, B.T. Johnson, \& M.P. Zanna (Eds.), The handbook of attitudes (pp.173-221). Mahwah, NJ: Erlbaum.

Batson, C.D., Schoenrade, P., \& Ventis, L. (1993). Religion and the individual. Oxford, England: Oxford University Press.

Baumeister, R. F., \& Leary, M. R. (1995). The need to belong: Desire for interpersonal attachments as a fundamental human motivation. Psychological Bulletin, 117, 497-529.

Brewer, M. B. (1979). In-group bias in the minimal intergroup situation: A cognitive-motivational analysis. Psychological Bulletin, 86, 307-324.

Brewer, M.B. (2009). Social identity and citizenship in a pluralistic society. In E. Borgida, C.M. Federico, \& J.L. Sullivan (Eds.), The political psychology of demographic citizenship. (pp.153-175).

Brewer M.B., \& Kramer R.M. (1985). The psychology of intergroup attitudes and behavior. Annual Review of Psychology, 36, 219-243.

Brooks, A.C. (2006). Who really cares: The surprising truth about compassionate conservatism-America's charity divide, who gives, who doesn't and why it matters. New York, NY: Basic Books.

Byrne , D. (1971). The attraction paradigm. New York: Academic Press.

Chambers, J. R., Baron, R. S., \& Inman, M. L. (2006). Misperceptions in intergroup conflict. Disagreeing about what we disagree about. Psychological Science, 17, 38-45. 
Chirumbolo, A., Areni, A., \& Sensales, G. (2004). Need for cognitive closure and politics: Voting, political attitudes, and attributional style. International Journal of Psychology, $39,245-253$.

De Cremer, D., \& Van Dijk, E. (2002). Reactions to group success and failure as a function of identification level: A test of the goal-transformation hypothesis in social dilemmas. Journal of Experimental Social Psychology, 38(5), 435-442.

De Cremer, D., \& Van Vugt, M. (2002). Intergroup and intragroup aspects of leadership in social dilemmas: A relational model of cooperation. Journal of Experimental Social Psychology, 38, 126-136.

Dovidio, J.F. (1984) Helping behavior and altruism: An empirical and conceptual overview. Advances in Experimental Social Psychology, 17, 361-427.

Ehlert, J., Ehlert, N., \& Merrens, M. (1973). The influence of ideological affiliation on helping behavior. Journal of Social Psychology, 89, 315-316.

Feldman, S., \& Stenner, K. (1997). Distinguishing threat and authoritarianism. Political Psychology, 18, 741-770.

Gergen, K.J., Gergen, M.M., \& Meter, K. (1972). Individual orientations to prosocial behavior. Journal of Social Isssues, 28, 105-130.

Graham, J. (2013). Beyond economic games: A mutualistic approach to the rest of moral life. [Commentary on Baumard, André, \& Sperber]. Behavioral and Brain Sciences, 36, 9192.

Graham, J., Nosek, B. A., \& Haidt, J. (2012). The moral stereotypes of liberals and conservatives: Exaggeration of differences across the political spectrum. PLoS ONE, 7, e50092. 
Graham, J., Haidt, J., \& Nosek, B.A. (2009). Liberals and conservatives rely on different sets of moral foundations. Journal of Personality and Social Psychology, 95(5), 1029-1046.

Graham, J. \& Haidt, J. (2011). Chapter 1: Sacred values and evil adversaries: A moral foundations approach. In M. Mikulincer \& P.R. Shaver (Eds.), The social psychology of morality: Exploring the causes of good and evil. New York: American Psychological Association.

Graham, J., Meindl, P., Koleva, S., Iyer, R., \& Johnson, K. (in Press) When values and behavior conflict: Moral pluralism and intrapersonal moral hypocrisy, Social and Personality Psychology Compass.

Graham, J., Nosek, B. A., Haidt, J., Iyer, R., Koleva, S., \& Ditto, P. H. (2011). Mapping the moral domain. Journal of Personality and Social Psychology, 101, 366-385.

Haidt, J. (2012). The righteous mind: Why good people are divided by politics and religion. New York, NY: Pantheon Books.

Haidt, J., \& Graham, J. (2007). When morality opposes justice: Conservatives have moral intuitions that liberals may not recognize. Social Justice Research, 20, 98-116.

Haidt, J., Graham, J., \& Joseph, C. (2009). Above and below left-right: Ideological narratives and moral foundations. Psychological Inquiry, 20(2-3), 110-119.

Haidt, J., Rosenberg, E., \& Hom, H. (2003). Differentiating diversities: Moral diversity is not like other kinds. Journal of Applied Social Psychology, 33(1), 1-36.

Hetherington, M.J., and Weiler, J.D. (2009). Authoritarianism \& polarization in American politics. Cambridge, UK: Cambridge University Press.

Hofmann, W., Wisneski, D. C., Brandt, M. J., \& Skitka, L. J. (2014). Morality in everydaylife. Science, 345, 1340-1343. 
Hogg, M. A., \& Sunderland, J. (1991). Self-esteemand intergroup discrimination in the minimal group paradigm. British Journal of Social Psychology, 30, 51-62.

Hornstein, H.A., (1982). Promotive tension: Theory and research. In V. Derlega, \& J. Grzelak (Eds.), pp. 229-248. New York: Academic Press.

Hunter, J.D. (1991). Culture wars: The struggle to define America. New York, NY: Basic.

Inbar, Y., Pizarro, D.A., \& Bloom, P. (2009). Conservatives are more easily disgusted than liberals. Cognition and Emotion, 23, 714-728.

Jost, J.T. (2006). The end of the end of ideology. American Psychologist, 61, 651-670.

Jost, J.T., Banaji, M.R., \& Nosek, B.A. (2004). A decade of system justification theory: Accummulated evidence of conscious and unconscious bolstering of the status quo. Political Psychology, 25, 881-919.

Jost, J.T., Fitzsimons, G., \& Kay, A.C. (2004). The ideological animal: A system justification view. In J. Greenberg, S.I. Koole, \& T. Pyszcyznki (Eds.), Handbook of experimental existential psychology (pp. 263-283). New York: Guilford.

Jost, J. T., Glaser, J., Kruglanski, A. W., \& Sulloway, F. J. (2003). Political conservatism as motivated social cognition. Psychological Bulletin, 129, 339-375.

Kollock, P. (1998). Social dilemmas: The anatomy of cooperation. Annual Review of Sociology, 24, 183-214.

Lakoff, G. (2002). Moral politics: How liberals and conservatives think. Chicago: University of Chicago Press.

Lennon, J. (1971). Imagine. Imagine [Vinyl]. New York: Apple.

McClintock, C. G. \& Van Avermaet, E. (1982). Social values and rules of fairness: A theoretical perspective, In V.J. Derlega \& J.L. GrzelakJ. L. (Eds.) Cooperation and helping 
behaviour: Theories and research (pp. 43-71) New York, NY: New York Academic Press.

Meindl, J. R. and Lerner, M. J. (1984). Exacerbation of extreme responses to an outgroup. Journal of Personality and Social Psychology, 47. 71-84.

Mondak, J.J. (2010). Personality and the foundations of political behavior. Cambridge, UK: Cambridge University Press.

Norenzayan, A., \& Shariff, A. F. (2008). The origin and evolution of religious prosociality. Science, 322, 58-62.

Piliavin, J.A., Dovidio, J.F., Gaertner, S.L., \& Clark, R.D., III. (1981). Emergency intervention. New York: Academic.

Pratto, F., Sidanius, J, Stallworth, L.M., \& Malle, B.F. (1994). Social dominance orientation: A personality variable predicting social and political attitudes. Journal of Personality and Social Psychology, 67(4), 741-763.

Rathbun, B.C. (2007). Hierarchy and community at home and abroad evidence of a common structure of domestic and foreign policy beliefs in American elites. Journal of Conflict Resolution, 51, 379-407.

Rosenbaum , M. E. (1986). The repulsion hypothesis: On the nondevelopment of relationships. Journal of Personality and Social Psychology, 51, 1156-1166.

Ross, M. \& Sicoly, F. (1979). Egocentric biases in availability and attribution. Journal of Personality and Social Psychology, 37, 322-336.

Schacter, D. (2003). The seven sins of memory. Annals of the New York Academy of Sciences, 1001, 226-239. 
Schlenker, B.R., Chambers, J.R., \& Le, B.M. (2012). Conservatives are happier than liberals ,but why? Political ideology, personality, and life satisfaction. Journal of Research in Personality, 46(2), 127-146.

Schwartz, S.H., Caprara, G.V., \& Vecchione, M. (2010). Basic personal values, core political values and voting: A longitudinal analysis. Political Psychology, 31, 421-452.

Sheldon, K.M., \& Nichols, C.P. (2009). Comparing democrats and republicans on intrinsic and extrinsic values. Journal of Applied Social Psychology, 39, 589-623.

Shepperd, J., Malone, W., \& Sweeny, K. (2008). Exploring causes of the self-serving bias. Social and Personality Psychology Compass, 2(2), 895-908.

Sidanius, J., \& Pratto, F. (1999). Social dominance: An intergroup theory of social hierarchy and oppression. Cambridge, UK: Cambridge University Press.

Sowell, T. (2002). A conflict of visions: The ideological origins of political struggles. New York: Basic Books.

Tajfel, H. and Billig, M. G. (1974). Familiarity and categorization in intergroup behaviour. Journal of Experimental Social Psychology, 10, 159-170.

Tajfel, H. and Turner, J. C. (1979). An integrative theory of intergroup conflict. In: W. G. Austin and S. Worchel (Eds.) 7he Social Psychology of Intergroup Relations. Monterey, CA: Brooks/ Cole.

Tajfel, H. and Turner, J. C. (1986). The social identity theory of inter-group behavior. In S. Worchel and L. W. Austin (eds.), Psychology of Intergroup Relations. Chigago: NelsonHall.

Valdesolo, P., \& DeSteno, D. (2007). Moral hypocrisy: Social groups and the flexibility of virtue. Psychological Science, 18, 689-690. 
Valdesolo, P., \& DeSteno, D. (2008). The duality of virtue: Deconstructing the moral hypocrite. Journal of Experimental Social Psychology, 44, 1334-1338.

Van Lange, P. A. M. (2000) Beyond self-interest: A set of propositions relevant to interpersonal orientations, European review of social psychology, 11, 297-331.

Van Lange, P.A.M., Bekkers, R., Chirumbolo, A., \& Leone, L. (2012). Are conservatives less likely to be prosocial than liberals? From games to ideology, political preferences, and voting. European Journal of Personality, 26(5), 461-473.

Van Lange, P.A.M., Otten, W., De Bruin, E., \& Joireman, J. (1997). Development of prosocial, individualistic, and competitve orientations: Theory and preliminary evidence. Journal of Personality and Social Psychology, 73, 733-746.

Van Leeuwen, F., \& Park, J.H. (2009). Perceptions of social dangers, moral foundations, and political orientation. Personality and Individual Differences, 47(3), 169-173.

Wilder, D. A. (1981). Perceiving persons as a group: Categorization and ingroup relations. In D. L. Hamilton (Ed.), Cognitive processes in stereotyping and intergroup behavior (pp. 213257). Hillsdale, NJ:Erlbaum.

Wilson, D.S., Van Vugt, M. \& O'Gorman, R. (2008) Multilevel Selection Theory and Major Evolutionary Transitions: Implications for Psychological Science. Current Directions in Psychological Science, 17(1), 6-9. 
Appendix A: Study 1a/1b Scenarios and Questionnaires

\section{Moral Foundations Questionnaire (Loyalty (L) and Fairness (F) subscales only)}

- When you decide whether something is right or wrong, to what extent is the following relevant to your thinking? ( $1=$ Not at all Relevant, $6=$ Extremely relevant)

- Whether or not some people were treated differently than others $(\mathrm{F})$

- Whether or not someones action showed love for his or her country (L)

- Whether or not someone acted unfairly $(F)$

- Whether or not someone did something to betray his or her group (L)

- Whether or not someone was denied his or her rights $(\mathrm{F})$

- Whether or not someone showed a lack of loyalty (L)

- Please read the following sentence and indicate your agreement or disagreement ( $1=$ Strongly Disagree, $6=$ Strongly Agree)

- When the government makes laws, the number one principle should be ensuring that everyone is treated fairly. $(\mathrm{F})$

- I am proud of my country's history. (L)

- Justice is the most important requirement for a society. (F)

- People should be loyal to their family members, even when they have done something wrong. (L)

- I think it's morally wrong that rich children inherit a lot of money while poor children inherit nothing. (F)

- It is more important to be a team player than to express oneself. (L)

\section{Prisoner's Dilemma Game}

Imagine you're at bar one day and you and (a person you don't know/your best friend) strike up a fun conversation. The conversation is flowing and so are the drinks. As the evening wears on, you both notice that the bartender leaves the cash drawer open every time he goes to the backroom for a few minutes. You start joking that it would be funny to steal the money and race out of the bar the next time he does it. You are both tipsy enough that this actually starts to seem like a good idea. In a whirlwind moment, the bartender goes to the back and the two of you grab the cash and race out of the bar. You run a few blocks together and then collapse panting and laughing. You stare at each other barely able to believe that you actually did it!

After running, the effects of the booze start to wear off and you start to feel a bit uncomfortable about the whole thing. The two of you nod at each other than then head separate ways. You aren't 100 yards away from each other when two police cars pull up, one in front of each of you, and you are both arrested.

You are being held in separate cells and you cannot communicate with each other. You are offered a deal by the police and you have to decide what to do. You can either confess and testify on the part of the police, or you can deny taking part in the crime. The deal is this:

- If you confess and testify and the person you just met denies taking part in the crime, you go free and your "partner" goes to prison for ten years. 
- If the person you just met confesses and you deny participating in the crime, you go to prison for ten years and your "partner" goes free.

- If you both confess you will serve six years each.

- If you both deny taking part in the crime, you both go to prison for six months.

- It is more important to be a team player than to express oneself. (L)

\section{Prisoner's Dilemma Game}

Imagine that you and 9 people (that are your closest friends/you don't know and will never meet) are given $\$ 30$ each. Each person has a choice. You can give any portion of the $\$ 30$ you received to a common pool of money. The total amount contributed to the common pool will be multiplied by two and then split equally among all members, regardless of how much they put into the pool. However, everyone makes their decision independently and by themselves. You don't get to see or know what amount anyone else has contributed.

You can give any amount from $\$ 0-\$ 30$ to the common pool. How much you decide to give may be influenced by what you think your friends will do. How much money (from \$0-\$30) do you choose to contribute to the common pool?

\section{Social Value Orientation Scale}

In this set of questions, we ask you to imagine that you have been randomly paired with another person, whom we will refer to simply as the "other." Other is someone you do not know and that you will not meet in the future. Both you and Other will be making choices by selecting either the letter A, B, or C. Your own choices will produce points for yourself and Other. Likewise, Other's choice will produce points for him/her and for you. Every point has value: The more points you receive, the better for you, and the more points Other receives, the better for him/her.

Here's an example of how this task works.

Option A: You get 500, Other gets 100.

Option B: You get 500, Other gets 500.

Option C: You get 550, Other gets 300.

In this example, if you chose A you would receive 500 points and Other would receive 100 points; if you chose $\mathrm{B}$, you would receive 500 points and Other 500; and if you chose $\mathrm{C}$, you would receive 550 points and Other 300 . So, you see that your choice influences both the number of points you receive and the number of points the other receives.

Before you begin making choices, keep in mind that there are no right or wrong answers-choose the option that you, for whatever reason, prefer most. Also, remember that the points have value: The more of them you accumulate, the better for you. Likewise, from Other's point of view, the more points s/he accumulates, the better for him/her.

For the choice situation below, choose A, B, or C, depending on which column you prefer most. 
(NOTE - Items are presented in a random order)

Option A: You get 480, Other gets 80

Option B: You get 540, Other gets 280

Option C: You get 480, Other gets 480

Option A: You get 560, Other gets 300

Option B: You get 500, Other gets 500

Option C: You get 500, Other gets 100

Option A: You get 520, Other gets 520

Option B: You get 520, Other gets 120

Option C: You get 580, Other gets 320

Option A: You get 500, Other gets 100

Option B: You get 560, Other gets 300

Option C: You get 490, Other gets 490

Option A: You get 560, Other gets 300

Option B: You get 500, Other gets 500

Option C: You get 490, Other gets 90

Option A: You get 500, Other gets 500

Option B: You get 500, Other gets 100

Option C: You get 570, Other gets 110

Option A: You get 510, Other gets 510

Option B: You get 560, Other gets 300

Option C: You get 510, Other gets 110

Option A: You get 550, Other gets 300

Option B: You get 500, Other gets 100

Option C: You get 500, Other gets 500

Option A: You get 480, Other gets 100

Option B: You get 490, Other gets 490

Option C: You get 540, Other gets 300

\section{Political Identification Items}

1. Please indicate your political identity on social issues (e.g., abortion, gun control, gay rights).
a. I am strongly liberal on social issues
b. I am moderately liberal on social issues
c. I am slightly liberal on social issues
d. I am in the middle on social issues
e. I am slightly conservative on social issues 
f. I am moderately conservative on social issues

g. I am strongly conservative on social issues

2. Please indicate your political identity on economic issues (e.g., taxation, government spending).

a. I am strongly liberal on economic issues

b. I am moderately liberal on economic issues

c. I am slightly liberal on economic issues

d. I am in the middle on economic issues

e. I am slightly conservative on economic issues

f. I am moderately conservative on economic issues

g. I am strongly conservative on economic issues

3. Please indicate your overall political identity...

a. I am strongly liberal

b. I am moderately liberal

c. I am slightly liberal

d. I am in the middle

e. I am slightly conservative

f. I am moderately conservative

g. I am strongly conservative

4. What is your political identification?
a. Democrat
b. Republican
c. Independent-- I don't identify with a Party
d. Libertarian
e. Green
f. Other
g. Don't Know

5. What percent of people in your community do you believe share your political beliefs?

a. $0-100 \%$ in $5 \%$ increments 
Appendix A: Study 2 Scenarios and Questionnaires

\section{\#1: Family Disloyalty -- Weak Group Ties}

Imagine that you are one of five children and you have two brothers and two sisters. Your younger brother Bob is a hiring manager at a company called Orion and has been looking to hire a new research analyst. Your older brother Fred is currently unemployed and is applying for the research analyst position at Orion. Unfortunately, there is another more qualified candidate who is also applying for the position. In the end, your younger brother Bob decides not to hire your older brother Fred.

\section{\#2: Family Disloyalty -- Strong Group Ties}

Imagine that you are one of five children in a very close-knit family. You have two brothers and two sisters and the five of you have become very close friends in addition to being family. When you were ten years old, your parents were in a terrible car accident. Your mother was killed, and your father was paralyzed from the waist down, and confined to a wheel chair. The accident was devastating to your family, but it forced you and your siblings to learn how to care for one another and how to support yourselves by working odd jobs. Together you've been through bad times and good times, and these experiences have brought you closer over the years.

Your younger brother Bob is a hiring manager at a company called Orion and has been looking to hire a new research analyst. Your older brother Fred is currently unemployed and is applying for the research analyst position at Orion. Unfortunately, there is another more qualified candidate who is also applying for the position. In the end, your younger brother Bob decides not to hire your older brother Fred.

\section{\#3: Employee Defection -- Weak Group Ties}

Imagine that you are an employee at a small start up company called Galaxy which is directly competing with another company called Helio. Bob is one of your coworkers at Galaxy. Bob has recently been offered an opportunity to make more money at the rival company Helio. If Bob accepts the offer it will be personally beneficial to him but your company will lose a great deal of talent and expertise to its rival. In the end, your coworker Bob decides to accept the offer from Helio.

\section{\#4: Employee Defection -- Strong Group Ties}

Imagine that you are an employee at a small start up company called Galaxy which is directly competing with another company called Helio. Bob is one of your coworkers at 
Galaxy. The two of you have been at Galaxy from the beginning, when the company was founded with just seven employees. During your first year working together you were both afraid that the company might not survive. Several other companies changed their strategy to compete directly against Galaxy, which threw off all the financial projections and nearly led to bankruptcy. The competition was fierce, and for a while you were all putting in 18 hour days. However, by banding together, you've made it through the bad times, and got to share the good times. These experiences made you all feel closer to each other over the years.

Bob has recently been offered an opportunity to make more money at the rival company Helio. If Bob accepts the offer it will be personally beneficial to him, but your company will lose a great deal of talent and expertise to its rival. In the end, your coworker Bob decides to accept the offer from Helio.

\section{\#5: Employee Whistleblowing -- Weak Group Ties}

Imagine that you are an employee at a pharmaceutical company called Flaxo which is directly competing with another company called Kilo. Bob is one of your coworkers at Flaxo. Flaxo is currently doing a research trial on a new cancer treatment drug and the preliminary results indicate that the drug is not as effective as other medications currently on the market. The company's leadership knows that if these results are released to the press, the news would cause the stock price to plunge, and it would damage the company. They decide that since the findings are only preliminary, they have no obligation to release them to the press. However, Bob feels the company should be more transparent about the findings and feels that releasing the preliminary results might help the sick cancer patients find a better treatment option. In the end, your coworker Bob decides to leak the preliminary results to the press. He sends a copy of the study to a reporter, anonymously, with a note explaining the study's significance.

\section{\#6: Employee Whistleblowing -- Strong Group Ties}

Imagine that you are an employee at a pharmaceutical company called Flaxo which is directly competing with another company called Kilo. Bob is one of your coworkers at Flaxo. The two of you have been at Flaxo from the beginning when the company was founded with just seven employees. During your first year working together you were both terrified that the company might not survive against the competition so you worked together almost around the clock to ensure that the company was successful. It wasn't easy, but by banding together you've made it through good times and bad and these experiences have made you and fellow employees closer over the years. 
Flaxo is currently doing a research trial on a new cancer treatment drug and the preliminary results indicate that the drug is not as effective as other medications currently on the market. The company's leadership knows that if these results are released to the press, the news would cause the stock price to plunge, and it would damage the company. They decide that since the findings are only preliminary, they have no obligation to release them to the press. However, Bob feels the company should be more transparent about the findings and feels that releasing the preliminary results might help the sick cancer patients find a better treatment option. In the end, your coworker Bob decides to leak the preliminary results to the press. He sends a copy of the study to a reporter, anonymously, with a note explaining the study's significance.

\section{\#7: Team -- Weak Group Ties}

Imagine that you are a member of a recreational co-ed soccer team called the Eagles which is directly competing with another team called the Strikers. Bob is one of your team members on the Eagles. Bob is a strong asset to your team but has recently been offered an opportunity to have more playing time if he switches to the Strikers. If Bob accepts the offer it will be personally beneficial to him but your team could really suffer in return. In the end, your teammate Bob decides to switch to the Strikers.

\section{\#8: Team -- Strong Group Ties}

Imagine that you are a member of a recreational co-ed soccer team called the Eagles which is directly competing with another team called the Strikers. Bob is one of your team members on the Eagles and has been on the team with you for the past five years. The two of you were founding members of the team and you've been through a lot together. Last year your team lost its star player to a knee injury, and then did so poorly that it was almost forced down into a lower league. However, in the face of this threat your team really banded together. Everyone agreed to put a lot more time into training, and the hard work is starting to pay off. You were able to greatly improve your performance and now it's looking like you might even make it to the league championship.

Bob is a strong asset to your team but has recently been offered an opportunity to have more playing time if he switches to the Strikers. If Bob accepts the offer it will be personally beneficial to him but your team could really suffer in return. In the end, your teammate Bob decides to switch to the Strikers. 


\section{Evaluation Items:}

1. In the scenario you just read and were asked to imagine, who was Bob?
a. Your brother
b. Your coworker who worked with you at the start up company Galaxy
c. Your coworker at the Pharmaceutical company Flaxo
d. Your teammate on your soccer team, the Eagles

2. In the end, what did Bob decide to do? What action did he take?
a. Hired his brother over the other candidate
b. Hired the more qualified candidate instead of his brother
c. Stayed with your company Galaxy
d. Switched to the competing company Helio
e. Kept quiet about the preliminary results
f. Released the preliminary results to the press
g. Stayed on your team, the Eagles
h. Switched to the opposing team, the Strikers

3. In your opinion, how morally right or wrong were Bob's actions?

1: Not at all immoral

2: Very slightly immoral

3: Slightly immoral

4: Somewhat immoral

5: Moderately immoral

6: Very immoral

7: Extremely immoral

8: One of the most immoral things that could be done

4. In your opinion, how loyal or disloyal were Bob's actions?

1: Not at all disloyal

2: Very slightly disloyal

3: Slightly disloyal

4: Somewhat disloyal

5: Moderately disloyal

6: Very disloyal

7: Extremely disloyal

8: One of the most disloyal things that could be done

5. How do you feel about Bob? 
1: Extremely Positive

2: Very Positive

3: Moderately Positive

4: Slightly Positive

5: Slightly Negative

6: Moderately Negative

7: Very Negative

8: Extremely Negative 


\section{\#1: Family Disloyalty -- Weak Group Ties}

Imagine that you are one of five children and you have two brothers and two sisters. Your younger brother Bob is a hiring manager at a company called Orion and has been looking to hire a new research analyst. Your older brother Fred was laid off from his job last year and ever since then he's been working really hard to find a new job to support himself and his family. Fred is currently applying for the research analyst position at Orion, but he's competing for the job against another equally qualified candidate. Your younger brother Bob knows that Fred really needs the job and could be a good fit for the position, but he thinks that his boss might not be pleased if he hires someone from your family. In the end, your younger brother Bob decides not to hire your older brother Fred.

\section{\#2: Family Disloyalty -- Strong Group Ties}

Imagine that you are one of five children in a very close-knit family. You have two brothers and two sisters and the five of you have become very close friends in addition to being family. When you were ten years old, your parents were in a terrible car accident. Your mother was killed, and your father was paralyzed from the waist down, and confined to a wheel chair. The accident was devastating to your family, but it forced you and your siblings to learn how to care for one another and how to support yourselves by working odd jobs. Together you've been through bad times and good times, and these experiences have brought you closer over the years.

Your younger brother Bob is a hiring manager at a company called Orion and has been looking to hire a new research analyst. Your older brother Fred was laid off from his job last year and ever since then he's been working really hard to find a new job to support himself and his family. Fred is currently applying for the research analyst position at Orion, but he's competing for the job against another equally qualified candidate. Your younger brother Bob knows that Fred really needs the job and could be a good fit for the position, but he thinks that his boss might not be pleased if he hires someone from your family. In the end, your younger brother Bob decides not to hire your older brother Fred.

\section{\#3: Employee Defection -- Weak Group Ties}

Imagine that you are an employee at a small start up company called Galaxy which is directly competing with another company called Helio. Bob is one of your coworkers at Galaxy. Bob has recently been offered an opportunity to work for Helio. If Bob accepts the offer it will be personally beneficial to him, but it could really hurt your company. In particular, it appears that Bob may use his knowledge of your company's business strategy to help Helio outperform Galaxy in the market. In the end, your coworker Bob decides to accept the offer from Helio. 


\section{\#4: Employee Defection -- Strong Group Ties}

Imagine that you are an employee at a small start up company called Galaxy which is directly competing with another company called Helio. Bob is one of your coworkers at Galaxy. The two of you have been at Galaxy from the beginning, when the company was founded with just seven employees. During your first year working together you were both afraid that the company might not survive. Several other companies changed their strategy to compete directly against Galaxy, which threw off all the financial projections and nearly led to bankruptcy. The competition was fierce, and for a while you were all putting in 18 hour days. However, by banding together, you've made it through the bad times, and got to share the good times. These experiences made you all feel closer to each other over the years.

Bob has recently been offered an opportunity to work for Helio. If Bob accepts the offer it will be personally beneficial to him, but it could really hurt your company. In particular, it appears that Bob may use his knowledge of your company's business strategy to help Helio outperform Galaxy in the market. In the end, your coworker Bob decides to accept the offer from Helio.

\section{\#5: Employee Whistleblowing -- Weak Group Ties}

Imagine that you are an employee at a Pharmaceutical company called Flaxo which is directly competing with another company called Kilo. Bob is one of your coworkers at Flaxo. Flaxo is currently doing a research trial on a new cancer treatment drug and the preliminary results indicate that the drug may not be as effective as other medications currently on the market. Your company's leadership knows that if these results are released to the press, the news could end the drug's trial and cause your company's stock price to plunge. They decide that since the findings are only preliminary and the drug could still be helping some subsets of patients, Flaxo should wait until the final results are available to release them. However, Bob is afraid that the final results will be negative and so he believes that it would be personally beneficial for him to be the one to publicly release the preliminary findings-- even if it may hurt your company. In the end, your coworker Bob decides to share the preliminary results with the press.

\section{\#6: Employee Whistleblowing -- Strong Group Ties}

Imagine that you are an employee at a Pharmaceutical company called Flaxo which is directly competing with another company called Kilo. Bob is one of your coworkers at Flaxo. The two of you have been at Flaxo from the beginning when the company was founded with just seven employees. During your first year working together you were both terrified that the company might not survive against the competition so you worked together almost around the clock to ensure that the company was successful. It wasn't easy, but by banding together you've made it through good times and bad and these experiences have made you and fellow employees closer over the years. 
Flaxo is currently doing a research trial on a new cancer treatment drug and the preliminary results indicate that the drug may not be as effective as other medications currently on the market. Your company's leadership knows that if these results are released to the press, the news could end the drug's trial and cause your company's stock price to plunge. They decide that since the findings are only preliminary and the drug could still be helping some subsets of patients, Flaxo should wait until the final results are available to release them. However, Bob is afraid that the final results will be negative and so he believes that it would be personally beneficial for him to be the one to publicly release the preliminary findings-- even if it may hurt your company. In the end, your coworker Bob decides to share the preliminary results with the press.

\section{\#7: Team Disloyalty - Weak Group Ties}

Imagine that you are a member of a professional soccer team called the Eagles which is directly competing with another team called the Strikers. Bob is one of your team members on the Eagles. Bob is a strong asset to your team but because of a quirk in his contract, he could opt-out now and move to another team. He has been offered a position on the Strikers. Bob thinks that if he switches now, his absence on the Eagles and his addition to the Strikers will virtually guarantee that he'd win the championship. If Bob accepts the offer it will be personally beneficial to him but your team could really suffer. In the end, your teammate Bob decides to switch to the Strikers right before the finals.

\section{\#8: Team Disloyalty - Strong Group Ties}

Imagine that you are a member of a professional soccer team called the Eagles which is directly competing with another team called the Strikers. Bob is one of your team members on the Eagles and has been on the team with you for the past five years. The two of you were founding members of the team and you've been through a lot together. Last year your team lost its star player to a knee injury, and then did so poorly that you almost didn't make it to the finals. However, in the face of this threat your team really banded together. Everyone agreed to put a lot more time into training, and the hard work really paid off. You were able to greatly improve your performance and you made it all the way to the season finals before you lost at the championship match.

Bob is a strong asset to your team but because of a quirk in his contract, he could opt-out now and move to another team. He has been offered a position on the Strikers. Bob thinks that if he switches now, his absence on the Eagles and his addition to the Strikers will virtually guarantee that he'd win the championship. If Bob accepts the offer it will be personally beneficial to him but your team could really suffer. In the end, your teammate Bob decides to switch to the Strikers right before the finals. 


\section{Appendix D: Tables}

Table 1.

Study la Correlations between Politics and Social Dilemma Responses

\begin{tabular}{lllllll}
\hline Measure & $\begin{array}{l}\text { Econ } \\
\text { Politics }\end{array}$ & $\begin{array}{l}\text { Overall } \\
\text { Politics }\end{array}$ & $\begin{array}{l}\text { Prisoners } \\
\text { (anon) }\end{array}$ & $\begin{array}{l}\text { Prisoners } \\
\text { (friend) }\end{array}$ & $\begin{array}{l}\text { Public } \\
\text { Goods } \\
\text { (anon) }\end{array}$ & $\begin{array}{l}\text { Public } \\
\text { Goods } \\
\text { (friend) }\end{array}$ \\
\hline $\begin{array}{l}\text { Social } \\
\text { Politics }\end{array}$ & $.570^{* *}$ & $.770^{* *}$ & -.010 & -.068 & $-.093^{*}$ & -.075 \\
$\begin{array}{l}\text { Economic } \\
\text { Politics }\end{array}$ & & $.766^{* *}$ & -.017 & -.054 & -.080 & -.012 \\
$\begin{array}{l}\text { Overall } \\
\text { Politics }\end{array}$ & & & & & \\
& & .004 & -.103 & -.076 & -.028 \\
\hline
\end{tabular}

Note. ${ }^{*} \mathrm{p}<0.05, * * \mathrm{p}<0.01$ 
Frazier 75

Table 2.

Study la Correlations between Politics, Moral Foundation Scores, and Social Value Orientation Scores

\begin{tabular}{llll}
\hline Measure & MFQ Loyalty & MFQ Fairness & SVO \\
\hline Social Politics & $.390^{* *}$ & $-.194^{* *}$ & $.088^{* *}$ \\
Economic Politics & $.285^{* *}$ & $-.274^{* *}$ & $.106^{* *}$ \\
Overall Politics & $.385^{* *}$ & $-.275^{* *}$ & $.102^{* *}$ \\
MFQ Loyalty & & $.117^{* *}$ & $.098^{* *}$ \\
MFQ Fairness & & $-.116^{* *}$ \\
\hline
\end{tabular}

Note. $* \mathrm{p}<0.05, * * \mathrm{p}<0.01$ 
Table 3.

Study la Effects of Social Politics on Average Moral Foundations Scores (for Loyalty and Fairness) and Social Value Orientation Scores

\begin{tabular}{|c|c|c|c|c|c|c|c|c|c|c|}
\hline Measure & Libera & & Mode & & Conse & ative & ANO & Results & & \\
\hline & Mean & $S D$ & Mean & $S D$ & Mean & $S D$ & $N$ & $F$ & $p$ & $\eta_{p}^{2}$ \\
\hline Loyalty & 3.22 & .93 & 3.86 & .92 & 3.92 & .76 & 1215 & 218.20 & .0001 & .152 \\
\hline Fairness & 4.57 & .71 & 4.47 & .76 & 4.33 & .69 & 1215 & 47.26 & .0001 & .038 \\
\hline SVO & 1.31 & .51 & 1.35 & .54 & 1.39 & .55 & 1207 & 9.37 & .002 & .008 \\
\hline
\end{tabular}

Note. MFQ scores range from $1=$ Not at all Relevant (This consideration has nothing to do with my judgments of right or wrong) to $6=$ Extremely Relevant (This is one of the most important factors when I judge right and wrong).

Average Social Value Orientation scores range from 1-3: 1 = Mostly Prosocial decision making (giving the other the same amount as yourself), 2 = Mostly Egoistic decision-making (selecting the option which gives you the largest personal benefit), and 3= Mostly Competitive decisionmaking (selecting the option that maximizes the difference between yourself and the other person). On average lower values represent more cooperative scores. 
Table 4.

Study la Correlations between Moral Foundations Subscales, Social Value Orientation, and Social Dilemma Responses

\begin{tabular}{lllll}
\hline Measure & $\begin{array}{l}\text { Prisoners } \\
\text { (anon) }\end{array}$ & $\begin{array}{l}\text { Prisoners } \\
\text { (friend) }\end{array}$ & $\begin{array}{l}\text { Public Goods } \\
\text { (anon) }\end{array}$ & $\begin{array}{l}\text { Public Goods } \\
\text { (friend) }\end{array}$ \\
\hline MFQ Loyalty & -.023 & -.011 & -.070 & -.058 \\
MFQ Fairness & -.050 & .002 & .007 & .065 \\
$\begin{array}{l}\text { Social Value } \\
\text { Orientation }\end{array}$ & .057 & .007 & $-.171^{* *}$ & $-.219^{* *}$ \\
\hline
\end{tabular}

Note. ${ }^{*} \mathrm{p}<0.05, * * \mathrm{p}<0.01$ 


\section{Table 5.}

Study $1 b$ ANOVA Model Predicting Giving in the Public Goods Game from Condition, Instruction Format, Social Politics, and their Interactions

\begin{tabular}{lllll}
\hline Source & $d f$ & $F$ & Partial Eta-squared & $p$ \\
\hline Condition & 1 & 13.00 & .003 & $<0.0005$ \\
Instruction Format & 1 & 20.71 & .005 & $<0.0005$ \\
Social Politics & 1 & 38.43 & .009 & $<0.0005$ \\
Condition * Social Politics & 1 & 0.52 & $<.0005$ & 0.469 \\
Condition * Instruction Format & 1 & 0.41 & $<.0005$ & 0.523 \\
Social Politics * Instr. Format & 1 & 0.15 & $<.0005$ & 0.698 \\
Cond * Instr. Format * Social Politics & 1 & 0.34 & $<.0005$ & 0.563 \\
Error & 4275 & & & \\
\hline
\end{tabular}


Table 6.

Correlations between Politics and Public Goods Responses

\begin{tabular}{lllll}
\hline Measure & Econ Politics & Overall Politics & $\begin{array}{l}\text { Public Goods } \\
\text { (anon) }\end{array}$ & $\begin{array}{l}\text { Public Goods } \\
\text { (friend) }\end{array}$ \\
\hline Social Politics & $.563 * *$ & $.761 * *$ & $-.099 * *$ & $-.081^{* *}$ \\
$\begin{array}{l}\text { Economic } \\
\begin{array}{l}\text { Politics } \\
\text { Overall Politics }\end{array}\end{array}$ & $.750 * *$ & -.096 & $-.072 * *$ \\
& & $-.104 * *$ & $-.103^{* *}$ \\
\hline
\end{tabular}

Note. ${ }^{*} \mathrm{p}<0.05, * * \mathrm{p}<0.01$ 
Table 7.

Correlations between Politics and Prisoner's Dilemma Responses

\begin{tabular}{lll}
\hline Measure & Prisoner's Dilemma (anon) & Prisoner's Dilemma (friend) \\
\hline Social Politics & -.055 & $-.067^{*}$ \\
Economic Politics & -.007 & -.046 \\
Overall Politics & -.012 & -.058 \\
\hline
\end{tabular}

Note. ${ }^{*} \mathrm{p}<0.05, * * \mathrm{p}<0.01$ 
Frazier 81

Table 8.

Study $1 b$ Correlations between Politics, Moral Foundation Scores, and Social Value Orientation Scores

\begin{tabular}{llll}
\hline Measure & MFQ Loyalty & MFQ Fairness & SVO \\
\hline Social Politics & $.330^{* *}$ & $-.201^{* *}$ & $.086^{* *}$ \\
Economic Politics & $.256^{* *}$ & $-.272^{* *}$ & $.124^{* *}$ \\
Overall Politics & $.325^{* *}$ & $-.268^{* *}$ & $.124^{* *}$ \\
MFQ Loyalty & & $.185^{* *}$ & $.089^{* *}$ \\
MFQ Fairness & & $-.133^{* *}$ \\
\hline
\end{tabular}

Note. ${ }^{*} \mathrm{p}<0.05, * * \mathrm{p}<0.01$ 
Table 9.

Study $1 b$ Effects of Social Politics on Average Moral Foundations Scores (for Loyalty and Fairness) and Social Value Orientation Scores

\begin{tabular}{|c|c|c|c|c|c|c|c|c|c|c|}
\hline Measure & Libera & & Mode & & Conse & ative & ANO & Results & & \\
\hline & Mean & $S D$ & Mean & $S D$ & Mean & $S D$ & $N$ & $F$ & $p$ & $\eta_{p}^{2}$ \\
\hline Loyalty & 3.39 & .90 & 3.94 & .87 & 3.90 & .89 & 4375 & 534.30 & .0001 & .109 \\
\hline Fairness & 4.57 & .71 & 4.46 & .72 & 4.28 & .80 & 4374 & 183.20 & .0001 & .040 \\
\hline SVO & 1.32 & .50 & 1.37 & .55 & 1.42 & .58 & 4352 & 32.79 & .0001 & .007 \\
\hline
\end{tabular}

Note. MFQ scores range from $1=$ Not at all Relevant (This consideration has nothing to do with my judgments of right or wrong) to $6=$ Extremely Relevant (This is one of the most important factors when I judge right and wrong).

Average Social Value Orientation scores range from 1-3: 1 = Mostly Prosocial decision making (giving the other the same amount as yourself), 2 = Mostly Egoistic decision-making (selecting the option which gives you the largest personal benefit), and 3= Mostly Competitive decisionmaking (selecting the option that maximizes the difference between yourself and the other person). On average lower values represent more cooperative scores. 
Table 10.

Correlations between Moral Foundations Subscales, Social Value Orientation, and Social Dilemma Responses

\begin{tabular}{lllll}
\hline Measure & Prisoners (anon) & Prisoners (friend) & $\begin{array}{l}\text { Public Goods } \\
\text { (anon) }\end{array}$ & $\begin{array}{l}\text { Public Goods } \\
\text { (friend) }\end{array}$ \\
\hline MFQ Loyalty & .016 & .004 & $-.047^{*}$ & $-.086^{* *}$ \\
MFQ Fairness & .002 & .019 & $.056^{* *}$ & $.098^{* *}$ \\
$\begin{array}{l}\text { Social Value } \\
\text { Orientation }\end{array}$ & $.073^{*}$ & .023 & $-.188^{* *}$ & $-.168^{* *}$ \\
\hline
\end{tabular}

Note. ${ }^{*} \mathrm{p}<0.05, * * \mathrm{p}<0.01$ 
Table 11.

Linear Mixed-Model Results Predicting Study 2 Morality Ratings using REML

\begin{tabular}{llllll}
\hline Effect & Variance & $\boldsymbol{S D}$ & Estimate & $\boldsymbol{S E}$ & $\boldsymbol{t}$ \\
\hline Random effects & & & & & \\
$\quad$ Subject (Intercept) & 0.386 & 0.621 & & & \\
$\quad$ Prompt Topic (Intercept) & 0.133 & 0.365 & & & \\
$\quad$ Group Ties (Strong) & 0.069 & 0.263 & & & \\
$\quad$ Residual & 2.476 & 1.573 & & & \\
Fixed effects & & & & & \\
$\quad$ Intercept & & & 0.409 & 0.190 & 2.151 \\
$\quad$ Group Ties (Strong) & & & 0.086 & 0.029 & 2.959 \\
$\quad$ Social Politics & & -0.006 & 0.038 & -0.160 \\
$\quad$ Interaction of Group & & & & & \\
$\quad$ Ties (Strong) and Social & & & & & \\
$\quad$ Politics & & & & \\
\hline
\end{tabular}

Note. REML criterion at convergence: 7532.2. All results presented in the table above were found using the lmer package in $\mathrm{R}$ and the formula (moral group * socialpoliticalid $+(1$ | session_id) + (prompt $\mid$ group).

Also, when interpreting the random effects here it's helpful to keep in mind that each random effect allow us to assume a different "baseline" average morality score for each subject because each subject has given two ratings and we expect these ratings to be correlated. In the context of the mixed model we are assigning each subject a different intercept value. Together all of these random effects give structure to the error term in our regression model and allow us to account for variations due to individual differences and differences across the topics and manipulations. In terms of the random effects for prompt|group we are estimating different intercepts for different prompts nested within the group type. The fact that the variance and standard deviation of these residuals is small tells us that the random effects are not vastly different across subjects or across each scenario (prompt topic nested within group ties). 
Table 12.

Linear Mixed-Model Results Predicting Study 2 Loyalty Ratings using REML

\begin{tabular}{llllll}
\hline Effect & Variance & $\boldsymbol{S D}$ & Estimate & $\boldsymbol{S E}$ & $\boldsymbol{t}$ \\
\hline Random effects & & & & & \\
$\quad$ Subject (Intercept) & 0.882 & 0.939 & & & \\
$\quad$ Prompt Topic (Intercept) & 0.517 & 0.719 & & & \\
$\quad$ Group Ties (Strong) & 0.244 & 0.494 & & & \\
$\quad$ Residual & 2.773 & 1.665 & & & \\
Fixed effects & & & & & \\
$\quad$ Intercept & & & 0.580 & 0.378 & 9.142 \\
$\quad$ Group Ties (Strong) & & & 0.041 & 0.033 & 1.249 \\
$\quad$ Social Politics & & -0.021 & 0.040 & -0.522 \\
$\quad$ Interaction of Group Ties & & & & & \\
$\quad$ (Strong) and Social Politics & & & & \\
\hline
\end{tabular}

Note. REML criterion at convergence: 7970. All results presented in the table above were found using the lmer package in $\mathrm{R}$ and the formula (loyal group * socialpoliticalid + $(1 \mid$ session_id) + (prompt| group). 
Table 13.

Linear Mixed-Model Results Predicting Study 2 Positivity Ratings using REML

\begin{tabular}{llllll}
\hline Effect & Variance & $\boldsymbol{S D}$ & Estimate & $\boldsymbol{S E}$ & $\boldsymbol{t}$ \\
\hline Random effects & & & & & \\
$\quad$ Subject (Intercept) & 0.717 & 0.847 & & & \\
$\quad$ Prompt Topic (Intercept) & 0.270 & 0.520 & & & \\
$\quad$ Group Ties (Strong) & 0.028 & 0.167 & & & \\
$\quad$ Residual & 2.163 & 1.471 & & & \\
Fixed effects & & & & & \\
$\quad$ Intercept & & & 0.508 & 0.153 & 3.314 \\
$\quad$ Group Ties (High) & & 0.032 & 0.029 & 1.100 \\
$\quad$ Social Politics & & -0.019 & 0.034 & -0.539 \\
$\quad$ Interaction of Group Ties & & & & & \\
$\quad$ (High) and Social Politics & & & & \\
\hline
\end{tabular}

Note. REML criterion at convergence: 7499.9. All results presented in the table above were found using the lmer package in $\mathrm{R}$ and the formula (liking $\sim$ group * socialpoliticalid $+(1$ | session_id) + (prompt $\mid$ group). 
Table 14.

Linear Mixed-Model Results Predicting Study 3 Morality Ratings using REML

\begin{tabular}{llllll}
\hline Effect & Variance & $\boldsymbol{S D}$ & Estimate & $\boldsymbol{S E}$ & $\boldsymbol{t}$ \\
\hline Random effects & & & & & \\
$\quad$ Subject (Intercept) & 0.427 & 0.653 & & & \\
$\quad$ Prompt Topic (Intercept) & 0.390 & 0.625 & & & \\
$\quad \quad$ Group Ties (Strong) & 0.066 & 0.227 & & & \\
$\quad$ Residual & 3.166 & 1.779 & & & \\
Fixed effects & & & & & \\
$\quad$ Intercept & & & 0.752 & 0.333 & 8.278 \\
$\quad$ Group Ties (Strong) & & & 0.106 & 0.033 & 3.220 \\
$\quad$ Social Politics & & -0.047 & 0.044 & -1.067 \\
$\quad$ Interaction of Group & & & & & \\
$\quad$ Ties (High) and Social & & & & & \\
$\quad$ Politics & & & & & \\
\hline
\end{tabular}

Note. REML criterion at convergence: 8322.2. All results presented in the table above were found using the lmer package in $\mathrm{R}$ and the formula (moral group * socialpoliticalid $+(1$ | session_id) + (prompt | group). 
Table 15.

Linear Mixed-Model Results Predicting Study 3 Loyalty Ratings using REML

\begin{tabular}{llllll}
\hline Effect & Variance & $\boldsymbol{S D}$ & Estimate & $\boldsymbol{S E}$ & $\boldsymbol{t}$ \\
\hline Random effects & & & & & \\
$\quad$ Subject (Intercept) & 0.937 & 0.968 & & & \\
$\quad$ Prompt Topic (Intercept) & 0.765 & 0.875 & & & \\
$\quad$ Group Ties (Strong) & 0.102 & 0.319 & & & \\
$\quad$ Residual & 2.670 & 1.634 & & & \\
Fixed effects & & & & & \\
$\quad$ Intercept & & & 0.403 & 0.211 & 1.907 \\
$\quad$ Group Ties (Strong) & & & 0.032 & 0.033 & 0.960 \\
$\quad$ Social Politics & & -0.071 & 0.040 & -1.750 \\
$\quad$ Interaction of Group Ties & & & & & \\
$\quad$ (Strong) and Social Politics & & & & \\
\hline
\end{tabular}

Note. REML criterion at convergence: 8276.4. All results presented in the table above were found using the lmer package in $\mathrm{R}$ and the formula (loyal $\sim$ group * socialpoliticalid $+(1 \mid$ session_id) + (prompt $\mid$ group). 
Table 16.

Linear Mixed-Model Results Predicting Study 3 Negativity Ratings using REML

\begin{tabular}{llllll}
\hline Effect & Variance & $\boldsymbol{S D}$ & Estimate & $\boldsymbol{S E}$ & $\boldsymbol{t}$ \\
\hline Random effects & & & & & \\
$\quad$ Subject (Intercept) & 0.511 & 0.715 & & & \\
$\quad$ Prompt Topic (Intercept) & 0.239 & 0.489 & & & \\
$\quad \quad$ Group Ties (Strong) & 0.041 & 0.203 & & & \\
$\quad$ Residual & 1.896 & 1.377 & & & \\
Fixed effects & & & & & \\
$\quad$ Intercept & & & 0.892 & 0.262 & 18.697 \\
$\quad$ Group Ties (Strong) & & & 0.042 & 0.027 & 1.565 \\
$\quad$ Social Politics & & -0.030 & 0.034 & -0.888 \\
$\quad$ Interaction of Group & & & & & \\
$\quad$ Ties (High) and Social & & & & & \\
$\quad$ Politics & & & & \\
\hline
\end{tabular}

Note. REML criterion at convergence: 7483.9. All results presented in the table above were found using the lmer package in $\mathrm{R}$ and the formula (loyal $\sim$ group * socialpoliticalid + (1 | session_id) + (prompt $\mid$ group). 